Article

\title{
Recovery and Stabilization of Anthocyanins and Phenolic Antioxidants of Roselle (Hibiscus sabdariffa L.) with Hydrophilic Deep Eutectic Solvents
}

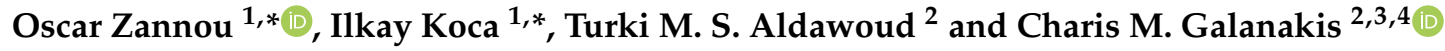 \\ 1 Department of Food Engineering, Ondokuz Mayis University, Samsun 55139, Turkey \\ 2 College of Science, King Saud University, Riyadh 11451, Saudi Arabia; tdawoud@ksu.edu.sa (T.M.S.A.); \\ cgalanakis@chemlab.gr (C.M.G.) \\ 3 Research \& Innovation Department, Galanakis Laboratories, 73131 Chania, Greece \\ 4 Food Waste Recovery Group, ISEKI Food Association, 1190 Vienna, Austria \\ * Correspondence: 17211163@stu.omu.edu.tr (O.Z.); itosun@omu.edu.tr (I.K.); Tel.: +90-531-817-37-83 (O.Z.); \\ +90-362-312-19-19 (I.K.)
}

Academic Editors: Gonzalo de Gonzalo and Mara Guadalupe Freire Martins Received: 24 July 2020; Accepted: 14 August 2020; Published: 14 August 2020

check for updates

\begin{abstract}
Deep eutectic solvents (DESs) have got huge interest as new green and sustainable solvents for the extraction of bioactive compounds from plants in recent decades. In the present study, we aimed to investigate the effectiveness of hydrophilic DES for the extraction of anthocyanin and polyphenol antioxidants from Roselle. A natural hydrophilic DES constituted of sodium acetate (hydrogen bond acceptor) and formic acid (hydrogen bond donor) designed to evaluate the total phenolic compound (TPC), total flavonoid (TFC), total anthocyanin (TACN), 2,2-diphenyl-1-picrylhydrazyl (DPPH) radical scavenging and ferric reducing antioxidant power (FRAP) values of Roselle. Distilled water, $70 \%$ ethanol, and $80 \%$ methanol used as conventional solvents for comparison. The results indicated that the DES prepared in molarity ratio $\left(\mathrm{SAFA}_{\mathrm{m}}\right)$ was the most efficient. Subsequently, this prominent DES selected for the optimization and the optimum extraction conditions were 1:3.6 molarity ratio, $0 \%$ additional water, and $10 \mathrm{~mL}$ solvent. TPC, TFC, TACN, FRAP, and DPPH radical scavenging at the optimum point were $233.26 \mathrm{mg} \mathrm{GAE} / \mathrm{g}, 10.14 \mathrm{mg} \mathrm{ECE} / \mathrm{g}, 10.62 \mathrm{mg}$ D3S/g, 493.45 $\mathrm{mmol} \mathrm{ISE} / \mathrm{g}$, and $343.41 \mathrm{mmol} \mathrm{TE} / \mathrm{g}$, respectively. The stability tests showed that anthocyanins were more stable in $\mathrm{SAFA}_{\mathrm{m}}$. These findings revealed that $\mathrm{SAFA}_{\mathrm{m}}$ is an effective green solvent for the extraction of polyphenols from various plants.
\end{abstract}

Keywords: roselle; deep eutectic solvent; anthocyanin; antioxidant; response surface methodology; green chemistry

\section{Introduction}

Roselle (Hibiscus sabdariffa L.) is one of the most popular species belonging to the Malvaceae family. They are highly desired by consumers, for containing several nutrients and phytochemical compounds that improve health. Roselle is essential for the prevention and treatment of hypertension, hepatitis, cardiovascular diseases, atherosclerosis, and diabetes [1-4]. The extracts had powerful effects on reducing high cholesterol, preventing cancer and hepatitis, and inhibiting pathogen microorganisms' growth $[2,5]$. Roselle's red calyces are processed to juice and tea, or incorporated in confectionary (e.g., chocolate) and dairy products as natural flavoring, and coloring agents. The calyces remain as the primary by-product and provide natural antioxidants and odorants [6-8].

Food and plant bioactives are nowadays very important in supporting the immune system within the COVID-19 pandemic era [9]. Roselle calyces contain bioactive compounds that are useful 
for human health such as gallic, syringic, caffeic, chlorogenic, neochlorogenic, cryptochlorogenic, ferulic acids, quercetin, naringenin, rutin, delphinidin 3-o-sambubioside, cyanidin 3-o-sambubioside, delphinidin-3-glucoside, cyanidin-3-kaempferol, and their glycosides with 5-(hydroxymethyl) [10-15]. Among the polyphenols present in Roselle calyces, anthocyanins are the most abundant flavonoid. The anthocyanins present in the Roselle have many pharmacological properties. They have demonstrated nephroprotective and antioxidative effects [16]. They could also be useful against ultraviolet radiation-induced cutaneous and ocular diseases [17]. Therefore, it is beneficial to extract polyphenols, especially anthocyanins, from Roselle.

The recovery of compounds from natural sources is typically conducted using the 5-Stages Universal Recovery Process: Pre-treatment, separation of macro- and micro-molecules, extraction, purification and product formation [18]. Among these stages, the third one (extraction) is the most essential one $[19,20]$. Most of the conventional extraction methods have drawbacks to require long extraction times and consumption of a high amount of organic solvent as well as apparent thermal degradation of phytochemicals [21-23]. The most common organic solvents used for the extraction of polyphenols are associated with possible inflammation, volatility, explosivity, toxicity, and environmental pollution [24]. Therefore, the development of environmentally friendly solvents with low toxicity and cost, as alternatives to the conventional organic solvents, became mandatory [25]. The extraction of phytochemicals with hydrotropic solvents is becoming the new trend [26,27].

Deep eutectic solvents (DESs) generated from the blend of two or more components consisting of hydrogen bond donor (HBD) and hydrogen bond acceptor (HBA), and establishing a supramolecular structure with hydrogen bonds [28]. DESs have much lower melting points than that of either single components $[29,30]$. They are mixtures of easily to be prepared, natural, renewable, non-toxic, and cheaper components [25,31,32]. They are also characterized by thermal and chemical stability, high solubility, low volatility, biodegradability, low vapor pressure, flexibility, strong biocompatibility, and designability $[33,34]$. Furthermore, DESs are worthwhile for the extraction of polyphenols since they provide higher extractability performance than the conventional solvents. They have been successfully employed for the extraction of polyphenols in many products [35]. Despite the suitability of DESs for polyphenols extraction, their high viscosity became a serious roadblock affecting their application and yield.

The high viscosity of DESs constitutes severe obstacles for their implementation in industry, even though the fluidity of these solvents might be increased by adding some quantities of water [28]. Therefore, the hydrophilic DESs have been developed, and the effects of water on their structure, as well as properties have been investigated [35-40]. For the extraction of polyphenolic compounds, diverse water contents either as a molar ratio or as a percentage have been reported [30,41-46]. Some authors researched the extraction of anthocyanins and polyphenolic antioxidants from Roselle calyces using conventional and citric acid-based DESs [14,17,47-49]. Furthermore, to the best of our knowledge, limited research has been published about the use of ultrasound-assisted extraction (UAE) for the recovery of polyphenolic antioxidants from Roselle calyces. In the present study, deep eutectic solvent-based ultrasound-assisted extraction of polyphenolics with antioxidant capacity from Roselle was investigated for the first time. The main aim of this study was to recover the maximum anthocyanin from Roselle using DES. For this purpose, a natural hydrophilic deep eutectic solvent (DES) designed and prepared using sodium acetate as HBA and formic acid as HBD. The effect of water addition on the extraction of polyphenols of Roselle was determined. The extraction using distilled water, aqueous ethanol and methanol as conventional solvents carried out for comparison. Also, the most prominent DES was chosen for the optimization using Box Behnken design along with Response Surface Methodology and for the stability of anthocyanin in DES. 


\section{Results and Discussion}

\subsection{Characterization of DESs}

\subsubsection{Viscosity}

The DESs prepared in molar and molarity ratios were encoded as $\mathrm{SAFA}_{0}$ and $\mathrm{SAFA}_{\mathrm{m}}$, respectively. Each DES was characterized by high viscosity ranged between 6.15 and 3651.6 mPa.s (Table 1). The presence of carboxyl groups and alkyl chains causes extremely high viscosity [35,50]. The pure $\mathrm{SAFA}_{0}(0 \%$ water content) was semi-solid at room temperature and displayed an extremely high viscosity of $3651.6 \mathrm{mPa}$.s. This high viscosity is associated with the $\mathrm{H}$ bonding network generated by the combination of sodium acetate and formic acid in eutectic terms. The addition of water decreased DES viscosity. The application of water in DESs has been reported to weaken and disintegrate the DESs nanostructure $[35,40]$. In the present study, the application of water decreased the viscosity to $61.6 \mathrm{mPa}$.s at $20 \%(v / v), 17.36 \mathrm{mPa} . \mathrm{s}$ at $40 \%(v / v), 10.81 \mathrm{mPa} . \mathrm{s}$ at $60 \%(v / v)$ and $7.66 \mathrm{mPa} . \mathrm{s}$ at $80 \%(v / v)$. The lowest viscosity was recorded in the DES prepared in molarity ratio (SAFA $)_{m}$, suggesting that it contained more water. Therefore, the interaction between sodium acetate and formic acid might be the lowest since high water concentration in DESs reduces the intermolecular and intramolecular reactions between the components constituting DESs [39,40,51].

Table 1. DESs preparation and corresponding viscosities.

\begin{tabular}{ccccc}
\hline DES. & Water Content \% & Molar Ratio & Molarity Ratio & Viscosity (mPa.s) \\
\hline SAFA $_{0}$ & 0 & $1: 2$ & - & $3651.60 \pm 14.60 \mathrm{a}$ \\
SAFA $_{20}$ & 20 & $1: 2$ & - & $61.60 \pm 5.98 \mathrm{~b}$ \\
SAFA $_{40}$ & 40 & $1: 2$ & - & $17.36 \pm 0.79 \mathrm{c}$ \\
SAFA $_{60}$ & 60 & $1: 2$ & - & $10.81 \pm 0.15 \mathrm{c}$ \\
SAFA $_{80}$ & 80 & $1: 2$ & - & $7.66 \pm 0.46 \mathrm{c}$ \\
SAFA $_{m}$ & - & - & $1: 2$ & $6.15 \pm 1.27 \mathrm{c}$ \\
\hline
\end{tabular}

Different letters $(\mathrm{a}, \mathrm{b}, \mathrm{c})$ in the same column indicate statistical differences $(p<0.05)$.

\subsubsection{FTIR}

The FTIR spectra of all the DESs studied were shown in Figure 1. The peaks at 2800 and $2650 \mathrm{~cm}^{-1}$ (Figure 1a) were assigned to $\mathrm{C}-\mathrm{H}$ stretching frequencies associated with formic acid and sodium acetate, respectively. The frequencies at 1650 and $1550 \mathrm{~cm}^{-1}$ were related to $\mathrm{C}=\mathrm{O}$ of formic acid and sodium acetate, respectively. The stretching of $\mathrm{C}-\mathrm{O}$ at $1350 \mathrm{~cm}^{-1}, \mathrm{CH}$ bending at 1250 and $1000 \mathrm{~cm}^{-1}$ and stretching of $\mathrm{C}-\mathrm{C}$ at $900 \mathrm{~cm}^{-1}$ were used to recognize sodium acetate. From spectroscopy data, it can be assumed that the strong $\mathrm{COOH}$...COOH bonds in sodium acetate and formic acid were broken down during the formation of sodium acetate and formic acid mixture to produce new strong intramolecular $\mathrm{COOH}$ bonds. This explains the low melting point and high viscosity of the pure $\mathrm{SAFA}_{0}$ [35].
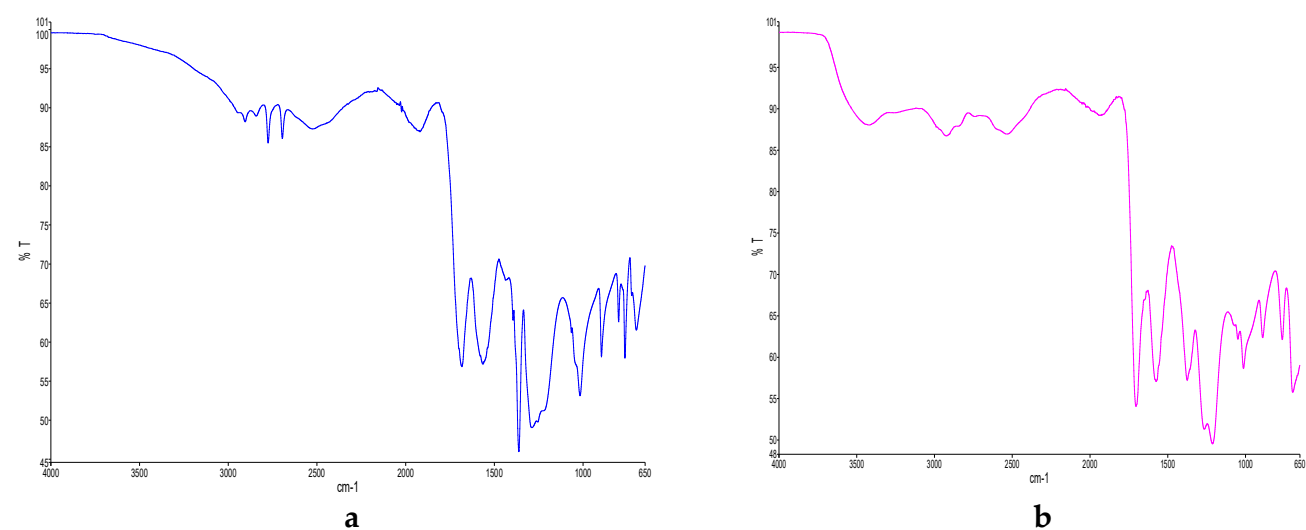

Figure 1. Cont. 

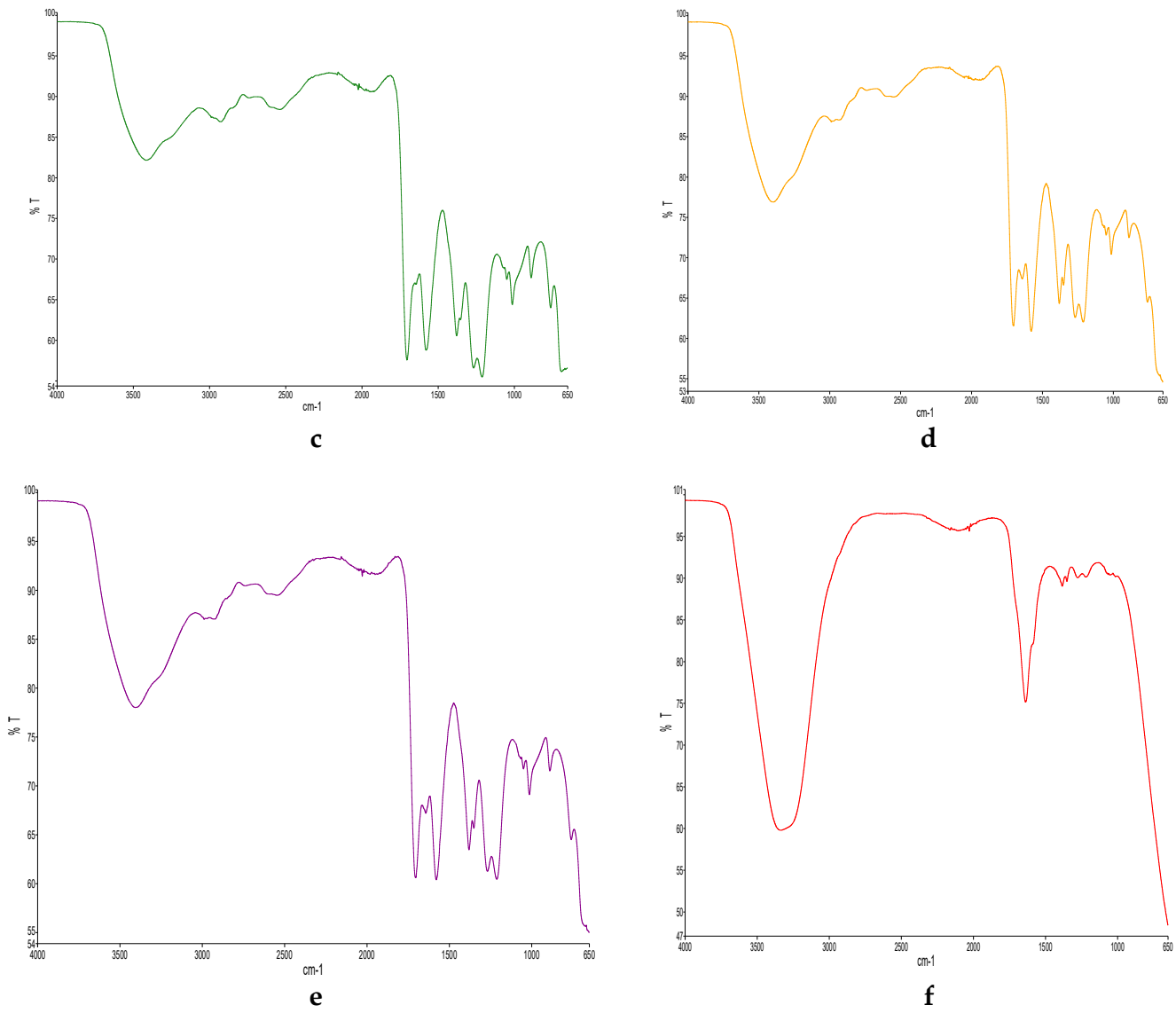

Figure 1. FTIR diagram of (a) $\mathrm{SAFA}_{0}$, (b) $\mathrm{SAFA}_{20}$, (c) $\mathrm{SAFA}_{40}$, (d) $\mathrm{SAFA}_{60}$, (e) $\mathrm{SAFA}_{80}$ and (f) $\mathrm{SAFA}_{\mathrm{m}}$.

After the addition of water, the stronger bonding between HBD and HBA was affected and weakened with the appearance of $\mathrm{O}-\mathrm{H}$ (Figure 1). The absence of $\mathrm{O}-\mathrm{H}$ in $\mathrm{SAFA}_{0}$ suggested that the mixture was too anhydrous. The stretching of $\mathrm{O}-\mathrm{H}$ at $3400 \mathrm{~cm}^{-1}$ appeared progressively in DESs, got higher as water content increased and became stronger in $\mathrm{SAFA}_{\mathrm{m}}$ (Figure $1 \mathrm{~b}-\mathrm{e}$ ). Similar phenomena have been reported in choline chloride and oxalic acid, as well as in choline chloride and glycol-based DESs, and might be due to alternative possibilities for $\mathrm{H}$ bonding in DES upon the introduction of water $[35,40]$. Hammond et al. (2017) have revealed that the introduction of a small quantity of water affected immensely the nanostructure of DES. However, FTIR analysis showed that the shape of spectra was kept after addition of $80 \%$ water. This indicates the tolerance of DES structure [35,52]. Nonetheless, $\mathrm{C}-\mathrm{H}$ stretching weakened upon addition of water and disappeared completely in $\mathrm{SAFA}_{\mathrm{m}}$.

\subsection{Evaluation of DESs Efficiency}

In the present study, sodium acetate:formic acid (1:2 molar ratio) was employed as a natural DES and coded as $\mathrm{SAFA}_{0}$ to extract polyphenolic compounds, especially anthocyanins and to evaluate the antioxidant activity of Roselle calyces. The major roadblock of DESs which limits their applications and efficiency for phytochemicals is the high viscosity. This fact reduces consequently the mass transfer and solubility of phenolic compounds $[42,53,54]$. To alleviate this constraint, DES sodium acetate:formic acid was diluted with 20, 40,60 and 80\% of water and encoded $\mathrm{SAFA}_{20}, \mathrm{SAFA}_{40}, \mathrm{SAFA}_{60}$, and $\mathrm{SAFA}_{80}$, respectively. Furthermore, another sodium acetate:formic acid-based DES was designed in molarity ratio 1:2 (SAFA $\mathrm{m}$ ), following the studies by the authors in [55], who have suggested the DESs betaine:tartaric acid and betaine:citric acid prepared in molarity ratio. In addition, for the purposes of comparison, distilled water, $70 \%$ ethanol and $80 \%$ methanol were used as conventional solvents. Roselle calyces were extracted with these solvents using ultrasound. The results of total phenolic 
(TPC), total flavonoid (TFC), total anthocyanin (TACN), DPPH radical scavenging and FRAP were shown in Table 2.

Table 2. TPC, TFC, TACN and antioxidant activity (DPPH radical scavenging and FRAP) of Roselle calyces using DES and conventional solvents.

\begin{tabular}{cccccc}
\hline Solvents. & $\begin{array}{c}\text { TPC, mg } \\
\text { GAE/g }\end{array}$ & $\begin{array}{c}\text { TFC, mg } \\
\text { ECE/g }\end{array}$ & $\begin{array}{c}\text { TACN, mg } \\
\text { D3S/g }\end{array}$ & $\begin{array}{c}\text { DPPH Radical } \\
\text { Scavenging, mmol } \\
\text { TE/g }\end{array}$ & $\begin{array}{c}\text { FRAP, mmol } \\
\text { ISE/g }\end{array}$ \\
\hline SAFA $_{0}$ & $6.95 \pm 0.41 \mathrm{~d}$ & $0.44 \pm 0.07 \mathrm{e}$ & $0.13 \pm 0.03 \mathrm{e}$ & $5.84 \pm 0.93 \mathrm{~g}$ & $58.99 \pm 3.42 \mathrm{c}$ \\
SAFA $_{20}$ & $141.30 \pm 8.53 \mathrm{c}$ & $2.28 \pm 0.13 \mathrm{~d}$ & $3.93 \pm 0.23 \mathrm{~d}$ & $52.55 \pm 5.78 \mathrm{f}$ & $435.61 \pm 31.04 \mathrm{a}$ \\
SAFA $_{40}$ & $198.49 \pm 3.22 \mathrm{~b}$ & $3.57 \pm 0.38 \mathrm{c}$ & $5.27 \pm 0.56 \mathrm{c}$ & $60.62 \pm 20.11 \mathrm{ef}$ & $448.99 \pm 57.01 \mathrm{a}$ \\
SAFA $_{60}$ & $199.83 \pm 10.54 \mathrm{~b}$ & $3.71 \pm 0.29 \mathrm{c}$ & $5.42 \pm 0.91 \mathrm{c}$ & $82.22 \pm 5.55 \mathrm{de}$ & $465.98 \pm 29.16 \mathrm{a}$ \\
SAFA $_{80}$ & $202.17 \pm 4.37 \mathrm{~b}$ & $3.75 \pm 0.28 \mathrm{c}$ & $5.85 \pm 0.29 \mathrm{bc}$ & $87.27 \pm 6.80 \mathrm{~d}$ & $484.06 \pm 2.73 \mathrm{a}$ \\
SAFA $_{\mathrm{m}}$ & $248.26 \pm 26.99 \mathrm{a}$ & $10.42 \pm 0.15 \mathrm{a}$ & $7.01 \pm 0.04 \mathrm{a}$ & $372.34 \pm 9.56 \mathrm{a}$ & $451.20 \pm 1.58 \mathrm{a}$ \\
distilled water & $141.23 \pm 17.96 \mathrm{c}$ & $2.09 \pm 1.04 \mathrm{~d}$ & $6.44 \pm 0.20 \mathrm{ab}$ & $313.41 \pm 13.91 \mathrm{c}$ & $391.91 \pm 9.33 \mathrm{~b}$ \\
$70 \%$ ethanol & $141.11 \pm 24.14 \mathrm{c}$ & $8.55 \pm 0.83 \mathrm{~b}$ & $6.80 \pm 0.68 \mathrm{a}$ & $354.97 \pm 27.41 \mathrm{ab}$ & $450.86 \pm 7.76 \mathrm{a}$ \\
$80 \%$ methanol & $139.83 \pm 32.38 \mathrm{c}$ & $2.95 \pm 0.19 \mathrm{~cd}$ & $5.68 \pm 0.46 \mathrm{bc}$ & $337.42 \pm 15.40 \mathrm{bc}$ & $467.75 \pm 21.76 \mathrm{a}$ \\
\hline
\end{tabular}

Different letters $(\mathrm{a}, \mathrm{b}, \mathrm{c}, \mathrm{d}, \mathrm{e}, \mathrm{f}, \mathrm{g})$ in the same column indicate statistical differences $(p<0.05)$.

Globally, when compared the efficiency of the solvents used in this study, the DESs were more efficient than the conventional solvents for the extraction of Roselle polyphenolics, except $\mathrm{SAFA}_{0}$ and $\mathrm{SAFA}_{20}$ (Table 2). The lowest results provided by SAFA 0 and SAFA 20 were due to their extremely viscosity (Table 1). The viscosity of DESs hinders the mass transfer in the extraction matrix, decreasing the extractability performance of DESs $[34,41,44,56]$. The highest TPC was detected with SAFA following $\mathrm{SAFA}_{80}, \mathrm{SAFA}_{60}, \mathrm{SAFA}_{40}$ and $\mathrm{SAFA}_{20}$, respectively. The TPC obtained with SAFA $\mathrm{m}$ was 43.11, 43.68 and $43.68 \%$ higher than the values obtained with distilled water, $70 \%$ ethanol and $80 \%$ methanol, respectively. Similar results have been figured out in rosemary, where TPC obtained with acid-based DESs was 15-18\% higher than ethanol [42]. Likewise, the highest TFC, TACN, DPPH radical scavenging and FRAP were determined with $\mathrm{SAFA}_{\mathrm{m}}$ and $\mathrm{SAFA}_{80}$. SAFA $\mathrm{m}$ yielded 1.22, 3.53 and 4.99-fold higher TFC than $70 \%$ ethanol, $80 \%$ methanol and distilled water, respectively. Similarly, the TFC has been well-extracted from saffron with lactic acid-based DES [57]. However, sodium acetate:formic acid provided higher yields of TPC of Roselle when compared to the yields of citric acid:glycerol $(24.79 \mathrm{mg}$

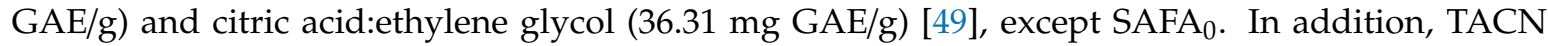
obtained with SAFA $m$ was 1.03, 1.09 and 1.23-fold higher than $70 \%$ ethanol, distilled water, and $80 \%$ methanol, respectively. Meanwhile, the values of TACN determined in this study were in accordance with the findings previously detected in Roselle with citric acid:glycerol (5.44 mg C3G/g) and citric acid:ethylene glycol (9.36 mg C3G/g) [49]. The high extraction yield of $\mathrm{SAFA}_{\mathrm{m}}$ is associated with the multiple hydrogen-bonding and low viscosity. The carboxyl group (-COOH) of formic acid presented more interactions between hydrogen-bonding [37]. The high efficiency of acid-based DESs for the extraction of polyphenolics have been proved and told to due to the $\mathrm{H}$-bonding interactions among DES components and the low viscosity [57-61]. SAFA $m$ was found to be an ideal medium for the extraction of Roselle polyphenolics, allowing a high mass transfer and solubility of anthocyanins.

\subsection{Optimization of DES and Extraction Conditions}

\subsubsection{Model Analysis}

The responses (total anthocyanin, total phenolic compound, DPPH radical scavenging, FRAP and total flavonoid values) and the coded independent factors of experimental points were shown in Table 3. A total of 17 experimental points was investigated. TPC was ranged from 105.81 to $233.20 \mathrm{mg} \mathrm{GAE} / \mathrm{g}$. The TFC values were found between 3.78 and $10.13 \mathrm{mg} \mathrm{ECE} / \mathrm{g}$, while TACN values were ranged from 6.50 and $10.90 \mathrm{mg}$ D3S/g. The values of FRAP were found between 305.86 and $493.88 \mathrm{mmol} \mathrm{ISE} / \mathrm{g}$, while DPPH radical scavenging values were ranged from 222.05 and $372 \mathrm{mmol} \mathrm{TE} / \mathrm{g}$. The highest 
TPC, TFC, TACN, FRAP and DPPH radical scavenging were detected at run 7 (SAFA $1: 4,0 \%$ additional water and $25 \mathrm{~mL}$ solvent). While, the lowest TPC and FRAP values were observed at run 5 (SAFA $\mathrm{m}_{\mathrm{m}} 1: 2.5,30 \%$ additional water and $25 \mathrm{~mL}$ solvent), and the lowest DPPH radical scavenging at run 11 (SAFA $1: 2.5,30 \%$ additional water and $25 \mathrm{~mL}$ solvent). Likewise, the lowest TFC and TACN values were detected in the run 4 (SAFA $1: 2.5,60 \%$ additional water and $40 \mathrm{~mL}$ solvent) and run $14\left(\mathrm{SAFA}_{\mathrm{m}}\right.$ 1:2.5, 30\% additional water and $25 \mathrm{~mL}$ solvent). The lowest values of the responses were figured out at the runs where DESs were prepared with additional water ranged between 30 and $60 \%$. At these experimental points, the viscosity was very low, indicating that the DES might lose its intrinsic characteristics and become a simple aqueous solution. It has been reported that a very low viscosity induce less hydrogen-bonding and decrease the extraction yield of phytochemical compounds [37,62]. The highest values were detected in the runs where DES did not require additional water. These findings revealed the importance of introduction of water in DES and indicated that the optimum DES will not have too low or too high viscosity. Moreover, the highest responses were obtained with molarity ratio 1:4.

Table 3. Coded Box-Behnken design with the analytical responses.

\begin{tabular}{ccccccccc}
\hline \multirow{3}{*}{ Run } & \multicolumn{3}{c}{ Coded Values } & \multicolumn{5}{c}{ Analytical Responses } \\
\cline { 2 - 9 } & $\mathbf{X}_{\mathbf{1}}$ & $\mathbf{X}_{\mathbf{2}}$ & $\mathbf{X}_{\mathbf{3}}$ & $\mathbf{Y}_{\mathbf{1}}$ & $\mathbf{Y}_{\mathbf{2}}$ & $\mathbf{Y}_{\mathbf{3}}$ & $\mathbf{Y}_{\mathbf{4}}$ & $\mathbf{Y}_{\mathbf{5}}$ \\
\hline 1 & 0 & +1 & -1 & 285.36 & 187.65 & 387.09 & 8.54 & 8.12 \\
2 & 0 & 0 & 0 & 225.09 & 115.48 & 318.29 & 8.54 & 7.49 \\
3 & -1 & 0 & -1 & 253.27 & 218.65 & 413.77 & 6.71 & 8.45 \\
4 & 0 & +1 & +1 & 295.17 & 180.24 & 350.69 & 3.78 & 8.34 \\
5 & 0 & 0 & 0 & 230.54 & 105.81 & 305.86 & 8.41 & 6.80 \\
6 & 0 & 0 & 0 & 231.89 & 121.86 & 325.44 & 7.31 & 7.12 \\
7 & +1 & -1 & 0 & 343.76 & 233.20 & 493.88 & 10.13 & 10.90 \\
8 & +1 & +1 & 0 & 297.80 & 206.55 & 395.52 & 8.95 & 7.5 \\
9 & 0 & -1 & +1 & 307.40 & 206.40 & 420.22 & 6.08 & 9.5 \\
10 & 0 & -1 & -1 & 339.30 & 265.03 & 466.24 & 8.78 & 8.74 \\
11 & 0 & 0 & 0 & 222.05 & 105.83 & 310.74 & 8.12 & 7.03 \\
12 & +1 & 0 & +1 & 255.15 & 213.36 & 371.96 & 4.41 & 8.46 \\
13 & -1 & -1 & 0 & 276.96 & 211.34 & 396.57 & 9.01 & 8.49 \\
14 & 0 & 0 & 0 & 230.54 & 205.30 & 315.35 & 7.56 & 6.50 \\
15 & +1 & 0 & -1 & 327.05 & 127.11 & 423.06 & 9.02 & 8.5 \\
16 & -1 & 0 & +1 & 279.46 & 177.04 & 339.79 & 4.37 & 8.30 \\
17 & -1 & +1 & 0 & 280.89 & 180.32 & 398.58 & 7.34 & 8.50 \\
\hline
\end{tabular}

$\mathrm{X}_{1}$ (Molarity ratio); $\mathrm{X}_{2}$ (Additional water, $\%$ ) and $\mathrm{X}_{3}$ (Solvent ratio, $\mathrm{mL}$ ). $\mathrm{Y}_{1}$ (DPPH radical scavenging, $\mathrm{mmol} \mathrm{TE} / \mathrm{g}$ ); $\mathrm{Y}_{2}$ (TPC, $\mathrm{mg} \mathrm{GAE} / \mathrm{g}$ ); $\mathrm{Y}_{3}$ (FRAP, $\mathrm{mmol} \mathrm{ISE} / \mathrm{g}$ ); $\mathrm{Y}_{4}$ (TFC, $\mathrm{mg} \mathrm{ECE} / \mathrm{g}$ ) and $\mathrm{Y}_{5}$ (TACN, $\mathrm{mg}$ D3S/g).

For the analysis of the optimization models, the regression coefficients were indicated at the least square for the second-order quadratic polynomial models. The stepwise option of response surface methodology was used to eliminate the non-significant parametric values [63]. The reduced second-order models in terms of actual factors for the responses such as TPC, TFC, TACN, FRAP and $\mathrm{DPPH}$ radical scavenging values of Roselle calyces as a function of molarity ratio $\left(\mathrm{X}_{1}\right)$, additional water $\left(\mathrm{X}_{2}\right)$ and solvent to solid ratio $\left(\mathrm{X}_{3}\right)$ were obtained as follows:

$$
\begin{gathered}
\text { TPC }=110.22+11.63 \mathrm{X}_{1}-20.25 \mathrm{X}_{2}-15.13 \mathrm{X}_{3}+13.00 \mathrm{X}_{2} \mathrm{X}_{3}+48.28 \mathrm{X}_{1}^{2}+49.03 \mathrm{X}_{2}^{2}+50.28 \mathrm{X}_{3}^{2} \\
\text { TFC }=7.60-1.75 \mathrm{X}_{3}-0.75 \mathrm{X}_{1} \mathrm{X}_{3}-0.75 \mathrm{X}_{2} \mathrm{X}_{3}+0.75 \mathrm{X}_{2}^{2}-2.05 \mathrm{X}_{3}^{2} \\
\text { TACN }=6.86+0.23 \mathrm{X}_{1}-0.60 \mathrm{X}_{2}+0.08 \mathrm{X}_{3}-0.91 \mathrm{X}_{1} \mathrm{X}_{2}+0.72 \mathrm{X}_{1}{ }^{2}+1.07 \mathrm{X}_{2}{ }^{2}+0.62 \mathrm{X}_{3}^{2} \\
\text { FRAP }=314.60-30.63 \mathrm{X}_{2}-26.13 \mathrm{X}_{3}+5.50 \mathrm{X}_{1} \mathrm{X}_{2}+43.33 \mathrm{X}_{1}{ }^{2}+62.58 \mathrm{X}_{2}^{2}+28.58 \mathrm{X}_{3}{ }^{2} \\
\mathrm{DPPH}=227.60+16.75 \mathrm{X}_{1}-13.50 \mathrm{X}_{2}-8.50 \mathrm{X}_{3}-12.50 \mathrm{X}_{1} \mathrm{X}_{2}-24.50 \mathrm{X}_{1} \mathrm{X}_{3}+10.50 \mathrm{X}_{2} \mathrm{X}_{3}+21.70 \mathrm{X}_{1}^{2}+49.50 \mathrm{X}_{2}{ }^{2}+29.20 \mathrm{X}_{3}{ }^{2}
\end{gathered}
$$


These equations showed up the response patterns for individual measurement and intricacy of sceneries. The higher and positive parametric values translate the more significant the weight of the governing variable is [64]. The results of the ANOVA showing the effects of different parametric values on the responses along with R2, adjusted R2, predicted R2, adequate precision and coefficient of variance $(\mathrm{CV})$ were assigned in Table 4 . The model developed for TPC, which provided higher $\mathrm{R}^{2}$ (0.9880) and adjusted $R^{2}(0.9725)$ was significant at $p<0.0001$. The $R^{2}$ and adjusted $R^{2}$ values displayed a good closeness, indicating that there was strong conformity between the experimental findings and predicted values. The CV of $4.71 \%$ revealed that the model was better reproducible for TPC, as CV expresses the standard deviation in percentage. The adequate precision ratio of 22.75 indicates that the model can be employed to explore the design because an adequate precision ratio higher than 4 is desirable. The lack of fit which was non-significant indicated that the developed model was a good fit at $\mathrm{F}$ value $1.70(p<0.3046)$. The predicted $\mathrm{R}^{2}$ of 0.8841 for TPC is in reasonable agreement with the adjusted $\mathrm{R}^{2}$ of 0.9725 ; i.e., the difference is less than 0.2 . The model developed for TFC was significant at $F$ value $30.84(p<0.0001)$ and had satisfactory $R^{2}(0.9655)$, adjusted $R^{2}(0.9211), C V(6.45 \%)$ and adequate precision (20.41). This model presented a non-significant lack of fit, conferring a good fitness to the model. Furthermore, the $\mathrm{R}^{2}$ and adjusted $\mathrm{R}^{2}$ of the model developed for the TFC were very close and higher which implicated there was great conformity between the experimental and predicted values. The predicted $\mathrm{R}^{2}$ of 0.9003 for TFC is in reasonable agreement with the adjusted $\mathrm{R}^{2}$ of 0.9438 ; i.e., the difference is less than 0.2. For TACN, the model was significant at F value $21.77(p<0.0003)$ and had desirable $\mathrm{R}^{2}(0.9655)$, adjusted $\mathrm{R}^{2}(0.9211), \mathrm{CV}(3.63 \%)$ and adequate precision (15.84). nonetheless, the predicted $R^{2}$ of 0.6098 is not as close to the adjusted $R^{2}$ of 0.9211 as one might normally expect. This may indicate a large block effect or a possible problem with the model and/or data. This model presented non-significant terms for lack of fit, indicating that the model was a good fit and adequate, since there was great conformity between the experimental and predicted values.

In relation to the model developed for DPPH radical scavenging, acceptable $\mathrm{R}^{2}(0.9864)$, adjusted $\mathrm{R}^{2}$ (0.9688), CV (2.57\%) and adequate precision (21.06) with significant terms at F value $58.26(p<0.0001)$. The predicted $\mathrm{R}^{2}$ of 0.8163 for DPPH radical scavenging is in reasonable agreement with the adjusted $\mathrm{R}^{2}$ of 0.9688 and a non-significant lack of fit approved the adequacy of the model. With respect to the model generated for FRAP, significant terms were found at F value $32.78(p<0.0001)$ with higher $R^{2}(0.9768)$, adjusted $R^{2}(0.9470), C V(3.10 \%)$ and adequate precision (18.13). These results indicated that there was strong conformity between the experimental findings and predicted values, and the model adequate and reproducible for FRAP values of Roselle calyces. In addition, the model generated for FRAP was good fit by providing a non-significant lack. These analytical findings proved that the parametric values for TPC, TFC, TACN, DPPH radical scavenging and FRAP values by response surface methodology can be used for the prediction and optimization stages [64] 
Table 4. ANOVA results for the reduced quadratic models.

\begin{tabular}{|c|c|c|c|c|c|c|c|c|c|c|c|c|c|c|c|}
\hline & \multicolumn{3}{|c|}{ TPC } & \multicolumn{3}{|c|}{ TFC } & \multicolumn{3}{|c|}{ TACN } & \multicolumn{3}{|c|}{ DPPH Radical Scavenging } & \multicolumn{3}{|c|}{ FRAP } \\
\hline & SS & F-Value & $p$-Value & SS & F-Value & $p$-Value & SS & F-Value & $p$-Value & SS & F-Value & $p$-Value & SS & F-value & $p$-Value \\
\hline model & $41,224.33$ & 63.93 & $<0.0001$ & 57.49 & 30.84 & $<0.0001$ & 16.54 & 21.77 & 0.0003 & $25,303.24$ & 56.28 & $<0.0001$ & $48,608,31$ & 32.78 & $<0.0001$ \\
\hline$X_{1}$ & 526.91 & 7.35 & 0.0301 & - & - & - & 2.07 & 24.51 & 0.0017 & 1919.57 & 38.42 & 0.0004 & - & - & - \\
\hline$x_{2}$ & $10,419.57$ & 145.42 & $<0.0001$ & - & - & - & 3.15 & 37.30 & 0.0005 & $10,107.63$ & 202.33 & $<0.0001$ & $13,644.21$ & 82.80 & $<0.0001$ \\
\hline$x_{3}$ & $10,289.55$ & 143.61 & $<0.0001$ & 20.17 & 97.35 & $<0.0001$ & 0.7286 & 8.63 & 0.0218 & 3544.30 & 70.95 & $<0.0001$ & 2683.79 & 16.29 & 0.0050 \\
\hline$X_{12}$ & - & - & - & - & - & - & 3.28 & 38.80 & 0.0004 & 625.00 & 12.51 & 0.0095 & 2500.00 & 15.17 & 0.0059 \\
\hline$x_{13}$ & - & - & - & 2.25 & 10.86 & 0.0132 & - & - & - & 2401.00 & 48.06 & 0.0002 & - & - & - \\
\hline$x_{23}$ & 676.00 & 9.43 & 0.0180 & 2.25 & 10.86 & 0.0132 & - & - & - & 441.00 & 8.83 & 0.0208 & - & - & - \\
\hline$x_{11}$ & 9812.53 & 136.95 & $<0.0001$ & - & - & - & 2.20 & 26.03 & 0.0014 & 1982.69 & 39.69 & 0.0004 & 7903.39 & 47.96 & 0.0002 \\
\hline$x_{22}$ & $10,119.79$ & 141.24 & $<0.0001$ & 2.06 & 9.96 & 0.0160 & 4.84 & 57.35 & 0.0001 & $10,400.38$ & 208.19 & $<0.0001$ & $16,486.87$ & 100.05 & $<0.0001$ \\
\hline$x_{33}$ & $10,642.42$ & 148.53 & $<0.0001$ & 17.69 & 85.42 & $<0.0001$ & 1.61 & 19.01 & 0.0033 & 3590.06 & 71.86 & $<0.0001$ & 3438.02 & 20.86 & 0.0026 \\
\hline residual & 501.55 & & & 1.45 & & & 0.59 & & & 349.70 & & & 1153.45 & & \\
\hline lack of fit & 280.75 & 1.70 & 0.3046 & 0.25 & 0.28 & 0.84 & 0.40 & 2.77 & 0.17 & 288.50 & 6.29 & 0.0540 & 920.25 & 5.26 & 0.0713 \\
\hline total & $41,725.88$ & & & 58.94 & & & 17.13 & & & $25,652.94$ & & & $49,761.76$ & & \\
\hline $\mathrm{R}^{2}$ & 0.9880 & & & 0.9754 & & & 0.9655 & & & 0.9864 & & & 0.9768 & & \\
\hline adjusted $R^{2}$ & 0.9725 & & & 0.9438 & & & 0.9211 & & & 0.9688 & & & 0.9470 & & \\
\hline predicted $\mathrm{R}^{2}$ & 0.8841 & & & 0.9003 & & & 0.6098 & & & 0.8163 & & & 0.6968 & & \\
\hline $\begin{array}{l}\text { adequate } \\
\text { precision }\end{array}$ & 22.75 & & & 20.41 & & & 15.84 & & & 21.06 & & & 18.13 & & \\
\hline C.V. \% & 4.71 & & & 6.45 & & & 3.63 & & & 2.57 & & & 3.40 & & \\
\hline
\end{tabular}

SS: Sum of squares. 


\subsubsection{Effects of Independent Variables on the Responses}

The linear, quadratic and interactions terms of the models on TPC, TFC, TACN, FRAP and DPPH radical scavenging of Roselle calyces were presented in Table 4 . The linear and quadratic terms had significant effects on TPC. However, the interaction terms of additional water and liquid to solid ratio had no significant effects on TPC with F values of $9.43(p<0.0180)$. The parametric value having the most impactful effects on TFC was linear term of liquid to solid ratio with F value of $97.35(p<0.0001)$, followed by the interaction terms of molarity ratio/liquid to ratio and additional water/liquid to solid ratio with $\mathrm{F}$ value of $10.86(p<0.0132)$, and the quadratic terms of additional water with $\mathrm{F}$ value $9.96(p<0.0160)$, and liquid to solid ratio with F value $85.42(p<0.0001)$, respectively. All linear terms and quadratic effects on TACN. Moreover, the interaction term of molarity ratio and additional water provided significant on TACN at F value $38.80(p<0.0004)$. As shown in Table 4 , all the linear, interaction and quadratic units showed significant effects on DPPH radical scavenging values of Roselle calyces Likewise, the linear units having the most impactful effects on FRAP were found to be additional water at F value 82.80 ( $p<0.0001)$, followed by liquid to solid ratio at $\mathrm{F}$ value 16.29 $(p<0.0050)$, while the most impactful quadratic units were additional water F value $100.05(p<0.0001)$, followed by molarity ratio F value $47.96(p<0.0002)$ and liquid to solid ratio F value $20.86(p<0.0026)$. In addition, the interaction of molarity ratio and additional water displayed significant effect on FRAP F value $15.17(p<0.0059)$.

The three-dimensional (3D) response surface plots of the models were used to interpret the effects of interactions between the variables on the responses (Figure 2). The 3D response surface plots showed that the TPC, TFC, TACN, FRAP and DPPH radical scavenging values were strongly influenced by molarity ratio and additional water. From the figures, it can be observed that an increase in molarity ratio induced a rapid increase in TPC, TFC, TACN, FRAP and DPPH radical scavenging values. This can be explained because the carboxyl group $(-\mathrm{COOH})$ and sodium cation $\left(-\mathrm{Na}^{+}\right)$from sodium acetate would combine with the carboxyl group $(-\mathrm{COOH})$ or the hydroxyl group $(-\mathrm{OH})$ of formic acid. With the lower molarity ratio of formic acid, there are many specific groups from HBA, which could not bond with the specific groups of HBD, leading to the precipitation of DESs [37,53]. Nonetheless, the effects of molarity ratio were moderate when compared to the effects of additional water.

As demonstrated in Figure 2, the addition of water led to a decrease in TPC, TFC, TACN, FRAP and DPPH radical scavenging values. The highest results were recorded with $0 \%$ additional water. However, a slight increase in TACN was observed in $40-60 \%$ of additional water. $0 \%$ additional water at the maximum response values might be explained because the DESs used in the present study were prepared as molarity terms. The hydrophilic DESs are greatly recommended for the isolation of bioactive compounds, facilitating their diffusion and solubility [61,62]. SAFAm was yet hydrophilic, implying that the further addition of water could be harmful to the DES and decrease the extraction performance. The hydrophilic DESs are easy to use, reduce the viscosity and preparation cost and increase polyphenolic extraction yields, nonetheless, a certain of amount of water could not be overpassed $[30,33,57,65]$. Adding more water weakens the interactions between the hydrogen-bonding of different components, affecting the extraction yield [37]. 

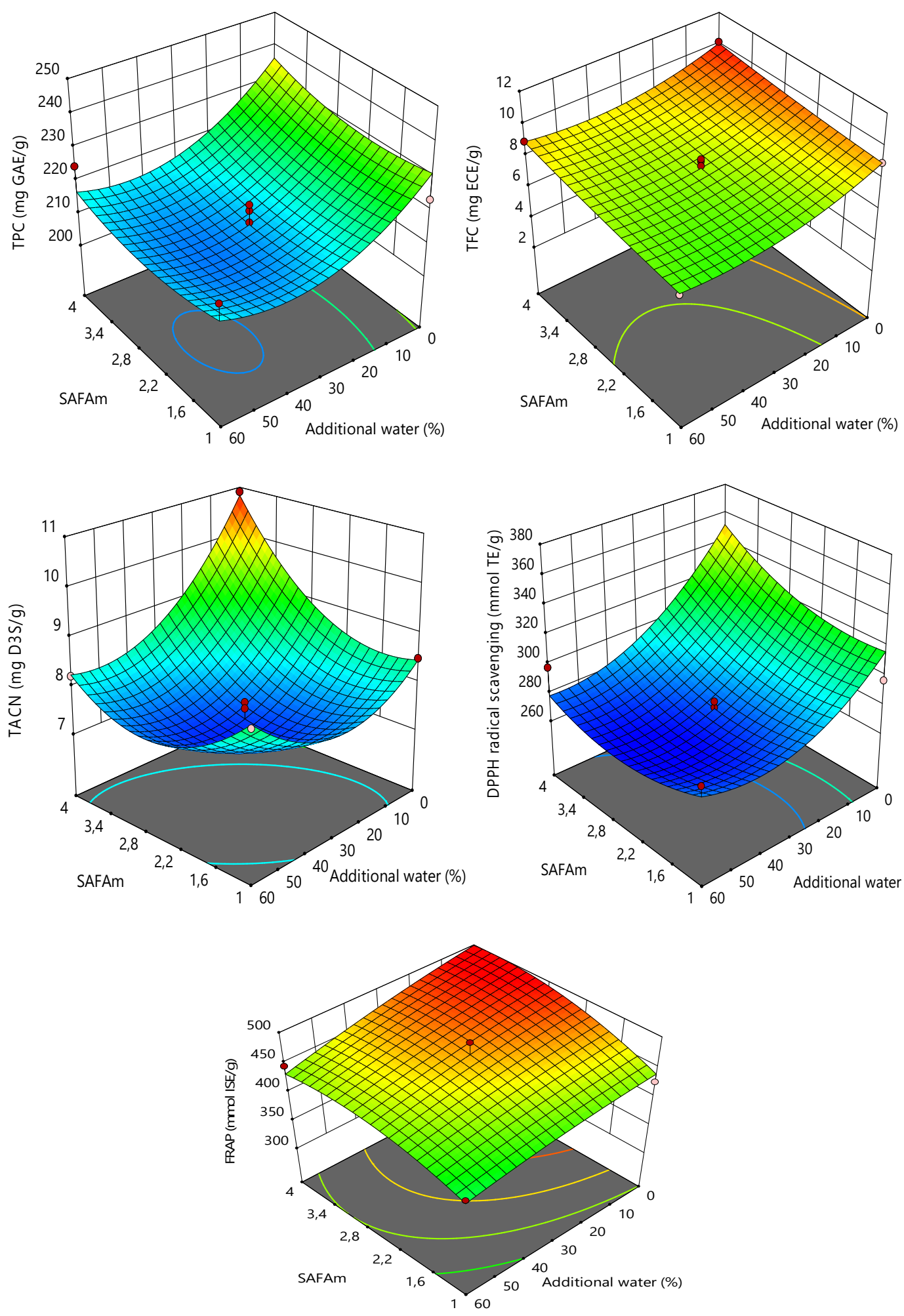

Figure 2. 3D response surface plots showing the effect of independent variables on the responses. 


\subsubsection{Multi-Response of the Optimization Process}

The response surface methodology was performed to optimize TPC, TFC, TACN, FRAP and DPPH radical scavenging values. The optimum conditions were 1:3.6 molarity ratio, $0 \%$ additional water and $10 \mathrm{~mL}$ solvent ratio. Under these optimum conditions, the predicted TPC, TFC, TACN, FRAP and DPPH radical scavenging values were $239.30 \mathrm{mg}$ GAE/g, $10.45 \mathrm{mg}$ ECE/g, $10.93 \mathrm{mg}$ $\mathrm{D} 3 \mathrm{~S} / \mathrm{g}, 503.83 \mathrm{mmol} \mathrm{ISE} / \mathrm{g}$ and $355.42 \mathrm{mmol} \mathrm{TE} / \mathrm{g}$, respectively. For confirmation, further analyses were performed under optimum conditions. The results were presented as $233.26 \mathrm{mg} \mathrm{GAE} / \mathrm{g}, 10.14 \mathrm{mg}$ ECE $/ \mathrm{g}$, $10.62 \mathrm{mg} \mathrm{D} 3 \mathrm{~S} / \mathrm{g}, 493.45 \mathrm{mmol}$ ISE/g and $343.41 \mathrm{mmol} \mathrm{TE} / \mathrm{g}$ for TPC, TFC, TACN, FRAP and DPPH radical scavenging, respectively.

\subsection{Efficiency of Response Surface Methodology on Total Anthocyanin}

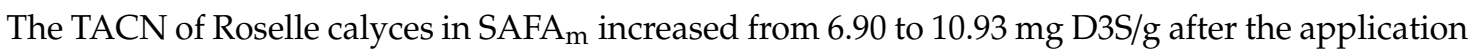
of response surface methodology. These values were found to be higher than the total anthocyanin previously detected in Roselle calyces which has been ranged between 1.22 and $2.3 \mathrm{mg} / \mathrm{g}[16,48]$. This is due not only to the origin and variety of the plant material but mostly to the use of DESs and UAE for the extraction. The DESs are natural and eco-friendly solvents which are prominent for the extraction of bioactive compounds including anthocyanins $[41,44,53,56,58,60,66]$. The DES (sodium acetate:formic acid) used in the present study extracted better anthocyanin from Roselle calyces. Furthermore, the application of UAE combined with DESs is well-adapted and accelerates the mass transfer of the analytes [67-69]. The effects of molarity ratio, additional water and solvent ratio on the response anthocyanin was well-represented by perturbation graphic generated using response surface methodology (Figure 3). As can be observed, the total anthocyanin of Roselle calyces behaved differently with variables. The curvature observed indicated that TACN was sensitive to all the variables. However, the TACN was mostly affected by molarity ratio and additional water, as these variables showed great variations (Figure 3 ).

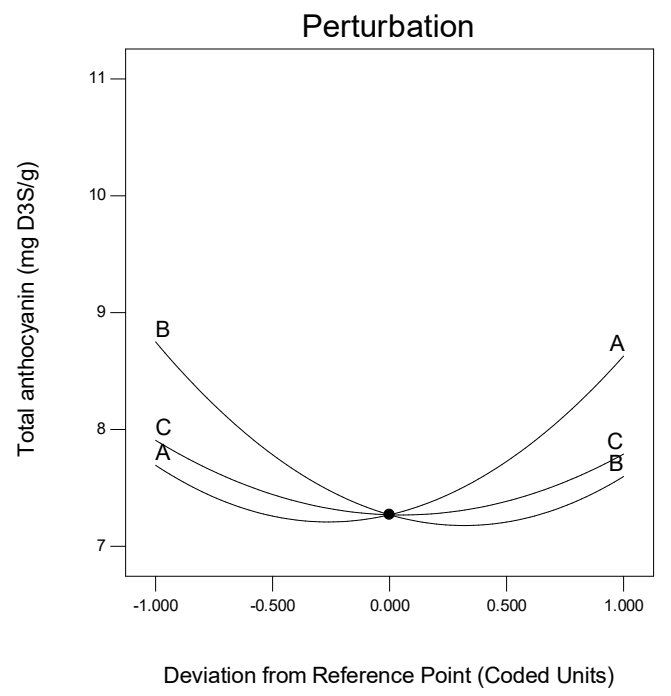

Figure 3. Perturbation graphic showing the effects of variables on total anthocyanin. 


\subsection{Stability of Antioxidant Properties of Roselle in $S A F A_{m}$}

The polyphenols recovered from different natural sources find applications in foods [70] and cosmetics [71] where stability is a critical factor for their successful implementation. The optimum experimental conditions figured out with response surface methodology were used to evaluate the heat and storage stabilities of TPC, TFC, TACN, DPPH radical scavenging and FRAP of Roselle.

\subsubsection{Thermal Stability}

The heat effects on TPC, TFC, TACN, DPPH radical scavenging and FRAP values of the DES extract of Roselle were determined by applying $40,60,80$ and $100{ }^{\circ} \mathrm{C}$ for 20, 40, 60, 80 and $100 \mathrm{~min}$. The first-order kinetics was determined for the thermal degradation of TPC, TFC, TACN and antioxidant properties of Roselle in SAFA $m$ (Figure 4). The TPC, TFC, DPPH radical scavenging and FRAP values of Roselle extracts showed strong stability in SAFA in all experimental temperatures and time. The thermal degradation started between 60 and $80 \mathrm{~min}$ of heating, except at $100{ }^{\circ} \mathrm{C}$ which induced a thermal degradation of TPC and TFC earlier at $60 \mathrm{~min}$, and $20 \mathrm{~min}$, respectively. The degradation rate was steeper for all the responses at $100{ }^{\circ} \mathrm{C}$ and $80 \mathrm{~min}$. These findings were in agreement with the previous thermal degradations of TPC, TFC and antioxidant activity reported in elderberry and lavender to be accentuated after 5-90 $\mathrm{min}$ at $75-150{ }^{\circ} \mathrm{C}$ [72-74]. TACN was more stable at 40, 60 and $80^{\circ} \mathrm{C}$ in $\mathrm{SAFA}_{\mathrm{m}}$ but decreased drastically at $100{ }^{\circ} \mathrm{C}$. Similarly, the thermal degradation of anthocyanin in aqueous extracts of Roselle has been reported to be crucial between 60 and $90^{\circ} \mathrm{C}[75,76]$. Generally, the phytochemical compounds with antioxidant properties in Roselle were found more stable in $\mathrm{SAFA}_{\mathrm{m}}$. The strong thermal stability behavior of polyphenols in $\mathrm{SAFA}_{\mathrm{m}}$ could be associated with a strong hydrogen network between extracts and DESs components [58]. However, the thermal degradation rate increased by augmenting both temperature and heat time. The first-order reaction constant $\mathrm{k}$ and activation energy for isothermal kinetics of anthocyanin degradation were assigned in Table 5. The values $\mathrm{k}$ figured out in this study confirmed the influence of temperature and time on anthocyanin. It was observed that $\mathrm{k}$ values increased with augmenting temperature from $2.39 \times 10^{-5}$ at $40{ }^{\circ} \mathrm{C}$ to $49.96 \times 10^{-5} \mathrm{~s}^{-1}$ to $100^{\circ} \mathrm{C}$ for times varying between 20 to $100 \mathrm{~min}$. Other authors have also mentioned that $\mathrm{k}$ values increased with augmenting temperature and time [14,58,76-78]. The activation energy (Ea) was ranged from 36.78 to $49.13 \mathrm{~kJ} / \mathrm{mol}$ and was slightly less than Ea values reported aqueous extracts of Roselle [75,76] and in blackcurrant juice [78].

Table 5. Effect of temperature and time on the $\mathrm{k}$ and Ea values of anthocyanin degradation kinetics of Roselle extracted with DES.

\begin{tabular}{|c|c|c|c|c|c|}
\hline \multirow{2}{*}{ Time (min) } & \multicolumn{4}{|c|}{$\mathbf{K}$} & \multirow{2}{*}{$\mathrm{Ea}(\mathrm{kJ} / \mathrm{mol})$} \\
\hline & $40{ }^{\circ} \mathrm{C}$ & $60^{\circ} \mathrm{C}$ & $80^{\circ} \mathrm{C}$ & $100^{\circ} \mathrm{C}$ & \\
\hline 20 & $\begin{array}{c}2.39 \times 10^{-5} \pm \\
3.73 \times 10^{-5} \mathrm{f}\end{array}$ & $\begin{array}{c}11.92 \times 10^{-5} \pm \\
6.32 \times 10^{-5} \mathrm{~d}\end{array}$ & $\begin{array}{l}9.00 \times 10^{-5} \pm \\
0.94 \times 10^{-5} \mathrm{de}\end{array}$ & $\begin{array}{c}49.96 \times 10^{-5} \pm \\
5.52 \times 10^{-5} \mathrm{a}\end{array}$ & $49.23 \pm 16.46 a$ \\
\hline 40 & $\begin{array}{c}2.58 \times 10^{-5} \pm \\
1.20 \times 10^{-5} \mathrm{f}\end{array}$ & $\begin{array}{l}6.48 \times 10^{-5} \pm \\
0.39 \times 10^{-5} \mathrm{ef}\end{array}$ & $\begin{array}{l}5.05 \times 10^{-5} \pm \\
4.63 \times 10^{-5} \mathrm{ef}\end{array}$ & $\begin{array}{c}33.82 \times 10^{-5} \pm \\
0.65 \times 10^{-5} \mathrm{c}\end{array}$ & $41.72 \pm 7.16 a$ \\
\hline 60 & $\begin{array}{c}3.42 \times 10^{-5} \pm \\
0.78 \times 10^{-5} \mathrm{f}\end{array}$ & $\begin{array}{l}5.05 \times 10^{-5} \pm \\
0.70 \times 10^{-5} \mathrm{ef}\end{array}$ & $\begin{array}{l}6.20 \times 10^{-5} \pm \\
1.48 \times 10^{-5} \mathrm{ef}\end{array}$ & $\begin{array}{c}33.68 \times 10^{-5} \pm \\
4.40 \times 10^{-5} \mathrm{c}\end{array}$ & $37.07 \pm 2.11 \mathrm{a}$ \\
\hline 80 & $\begin{array}{c}3.39 \times 10^{-5} \pm \\
0.72 \times 10^{-5} \mathrm{f}\end{array}$ & $\begin{array}{l}4.63 \times 10^{-5} \pm \\
2.21 \times 10^{-5} \mathrm{ef}\end{array}$ & $\begin{array}{c}7.14 \times 10^{-5} \pm \\
1.01 \times 10^{-5} \mathrm{def}\end{array}$ & $\begin{aligned} 32.79 & \times 10^{-5} \pm \\
2.31 & \times 10^{-5} \mathrm{c}\end{aligned}$ & $36.78 \pm 2.35 a$ \\
\hline 100 & $\begin{array}{c}3.12 \times 10^{-5} \pm \\
0.78 \times 10^{-5} \mathrm{f}\end{array}$ & $\begin{array}{l}6.67 \times 10^{-5} \pm \\
1.27 \times 10^{-5} \mathrm{ef}\end{array}$ & $\begin{array}{c}7.56 \times 10^{-5} \pm \\
1.45 \times 10^{-5} \mathrm{def}\end{array}$ & $\begin{array}{c}41.66 \times 10^{-5} \pm \\
2.88 \times 10^{-5} \mathrm{~b}\end{array}$ & $41.97 \pm 4.60 \mathrm{a}$ \\
\hline
\end{tabular}

Different letters $(\mathrm{a}, \mathrm{b}, \mathrm{c}, \mathrm{d}, \mathrm{e}, \mathrm{f})$ indicate statistical differences $(p<0.05)$. 


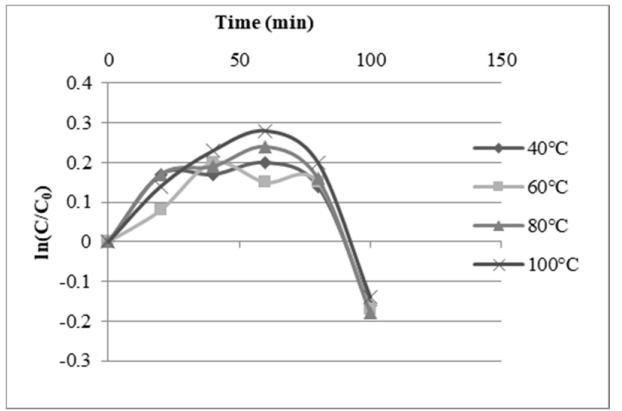

A

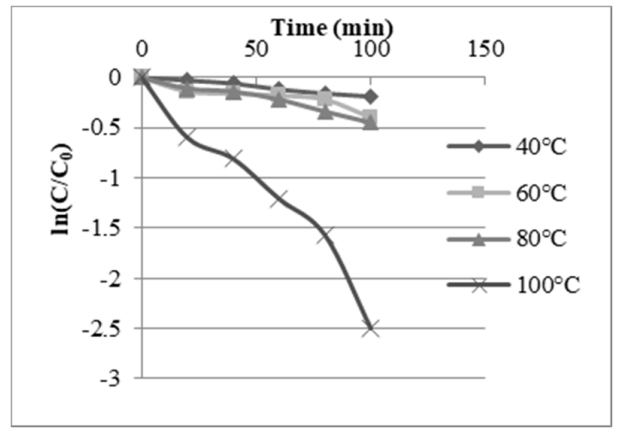

C

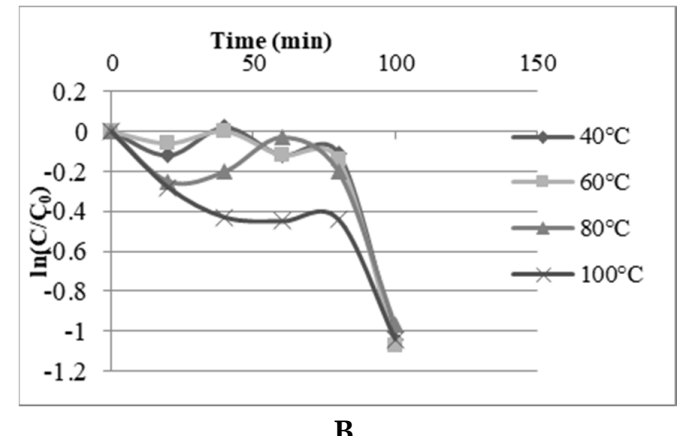

B

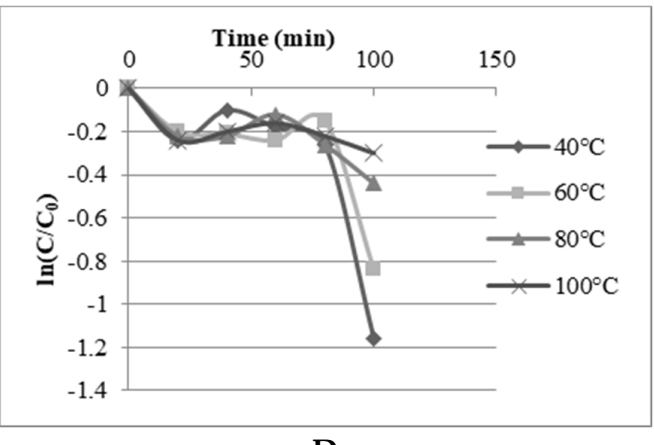

D

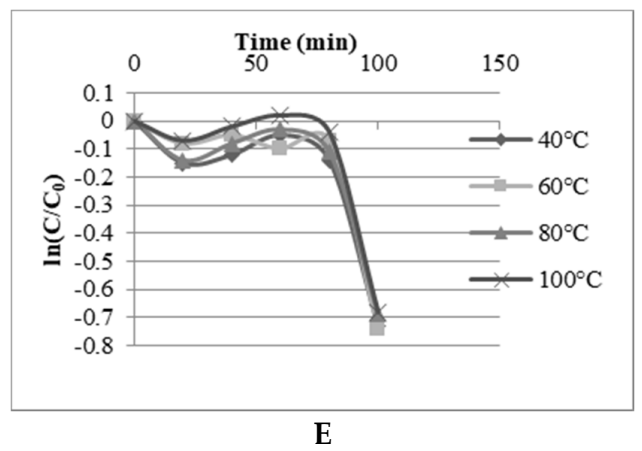

Figure 4. Stability of TPC (A), TFC (B), TACN (C), DPPH radical scavenging (D) and FRAP (E) values in SAFA.

\subsubsection{Stability of Total Anthocyanin during Storage}

The degradation of anthocyanin in $\mathrm{SAFA}_{\mathrm{m}}$ was investigated during eighteen days at room temperature $\left(20^{\circ} \mathrm{C}\right), 4^{\circ}$ and $-20^{\circ} \mathrm{C}$, and the results were represented in Figure 5 . The concentrations of anthocyanin decreased slowly in $\mathrm{SAFA}_{\mathrm{m}}$ with time at all temperatures. However, this decrease was steeper at higher temperature $\left(20^{\circ} \mathrm{C}\right)$. The degradation rates were $40.10,20.46$ and $19.25 \%$ at $20^{\circ} \mathrm{C}, 4{ }^{\circ} \mathrm{C}$ and $-20{ }^{\circ} \mathrm{C}$, respectively. The linear relation between the logarithm of total anthocyanins and time indicated

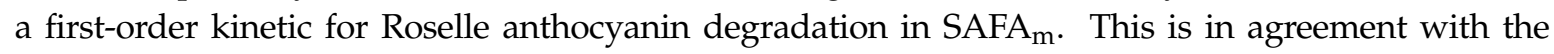
previous investigations in aqueous extracts of Roselle [14,75]. The anthocyanin degradation was too slow in $\mathrm{SAFA}_{\mathrm{m}}$, especially after 12 days, showing the strength of intramolecular and intermolecular reactions occurred between solute and $\mathrm{SAFA}_{\mathrm{m}}$. Nonetheless, the storage temperature had an influence on anthocyanin degradation (Table 6). As can be seen, the values of $\mathrm{k}$ varied from $1.29 \times 10^{-7}$ to $2.52 \times 10^{-7} \mathrm{~s}^{-1}$ at $-20^{\circ} \mathrm{C}$, from $1.47 \times 10^{-7}$ to $3.47 \times 10^{-7} \mathrm{~s}^{-1}$ at $4^{\circ} \mathrm{C}$ and from $2.73 \times 10^{-7}$ to $7.41 \times 10^{-7} \mathrm{~s}^{-1}$ at $20^{\circ} \mathrm{C}$. During the storage, the values of the first-order rate constant $(\mathrm{k})$ of the model increased 5.74-fold. Furthermore, the values of $\mathrm{t}_{1 / 2}$ were ranged $0.94 \times 10^{6}$ to $5.39 \times 10^{6} \mathrm{~s}$ and the highest $\mathrm{t}_{1 / 2}$ values were found at $-20{ }^{\circ} \mathrm{C}$ and $4{ }^{\circ} \mathrm{C}$, respectively. $\mathrm{k}$ values detected in this study were low and $\mathrm{t}_{1 / 2}$ values were higher when compared to $k$ and $t_{1 / 2}$ values reported in previous studies $[14,76]$. This indicated that $S A F A_{m}$ was more anthocyanin-protective during the storage when compared to water. 
Table 6. Effect of storage on the $\mathrm{k}$ and $\mathrm{t}_{1 / 2}$ values of anthocyanin degradation kinetics of Roselle extracted with DES.

\begin{tabular}{|c|c|c|c|c|c|c|c|c|c|c|c|c|}
\hline \multirow{2}{*}{$\begin{array}{c}\text { Temperature } \\
\left({ }^{\circ} \mathrm{C}\right)\end{array}$} & \multicolumn{2}{|c|}{3 Days } & \multicolumn{2}{|c|}{6 Days } & \multicolumn{2}{|c|}{9 Days } & \multicolumn{2}{|c|}{12 Days } & \multicolumn{2}{|c|}{15 Days } & \multicolumn{2}{|c|}{18 Days } \\
\hline & k & $t_{1 / 2}$ & $\mathrm{k}$ & $t_{1 / 2}$ & k & $t_{1 / 2}$ & k & $t_{1 / 2}$ & K & $t_{1 / 2}$ & $\mathrm{k}$ & $t_{1 / 2}$ \\
\hline 20 & $\begin{array}{c}4.34 \times 10^{-7} \pm \\
5.34 \times 10^{-8} \mathrm{a}\end{array}$ & $\begin{array}{l}1.61 \times 10^{6} \pm \\
1.92 \times 10^{5} \mathrm{~b}\end{array}$ & $\begin{array}{c}7.41 \times 10^{-7} \pm \\
3.29 \times 10^{-8} \mathrm{a}\end{array}$ & $\begin{array}{c}0.94 \times 10^{6} \pm \\
0.43 \times 10^{5} \mathrm{c}\end{array}$ & $\begin{array}{l}4.59 \times 10^{-7} \pm \\
1.55 \times 10^{-8} \mathrm{a}\end{array}$ & $\begin{array}{l}1.51 \times 10^{6} \pm \\
0.50 \times 10^{5} \mathrm{~b}\end{array}$ & $\begin{array}{l}4.34 \times 10^{-7} \pm \\
1.22 \times 10^{-8} \mathrm{a}\end{array}$ & $\begin{array}{c}1.60 \times 10^{6} \pm \\
0.45 \times 10^{5} \mathrm{c}\end{array}$ & $\begin{array}{c}3.95 \times 10^{-7} \pm \\
3.01 \times 10^{-9} \mathrm{a}\end{array}$ & $\begin{array}{l}1.87 \times 10^{6} \pm \\
1.75 \times 10^{5} \mathrm{~b}\end{array}$ & $\begin{array}{c}2.73 \times 10^{-7} \pm \\
1.72 \times 10^{-8} \mathrm{a}\end{array}$ & $\begin{array}{c}2.31 \times 10^{6} \pm \\
2.54 \times 10^{5} \mathrm{~b}\end{array}$ \\
\hline 4 & $\begin{array}{c}2.63 \times 10^{-7} \pm \\
0.96 \times 10^{-8} \mathrm{~b}\end{array}$ & $\begin{array}{c}2.63 \times 10^{6} \pm \\
0.98 \times 10^{5} \mathrm{a}\end{array}$ & $\begin{array}{l}3.31 \times 10^{-7} \pm \\
2.82 \times 10^{-8} \mathrm{~b}\end{array}$ & $\begin{array}{l}1.11 \times 10^{6} \pm \\
1.85 \times 10^{5} \mathrm{~b}\end{array}$ & $\begin{array}{l}1.51 \times 10^{-7} \pm \\
2.82 \times 10^{-8} \mathrm{~b}\end{array}$ & $\begin{array}{c}4.65 \times 10^{6} \pm \\
5.34 \times 10^{5} \mathrm{a}\end{array}$ & $\begin{array}{c}2.00 \times 10^{-7} \pm \\
7.31 \times 10^{-9} \mathrm{~b}\end{array}$ & $\begin{array}{l}3.47 \times 10^{6} \pm \\
1.28 \times 10^{5} \mathrm{~b}\end{array}$ & $\begin{array}{c}1.65 \times 10^{-7} \pm \\
2.14 \times 10^{-8} \mathrm{~b}\end{array}$ & $\begin{array}{c}4.25 \times 10^{6} \pm \\
5.72 \times 10^{5} \mathrm{a}\end{array}$ & $\begin{array}{l}1.47 \times 10^{-7} \pm \\
2.34 \times 10^{-8} \mathrm{~b}\end{array}$ & $\begin{array}{c}4.49 \times 10^{6} \pm \\
8.12 \times 10^{5} \mathrm{a}\end{array}$ \\
\hline-20 & $\begin{array}{l}2.52 \times 10^{-7} \pm \\
3.33 \times 10^{-8} \mathrm{~b}\end{array}$ & $\begin{array}{c}2.78 \times 10^{6} \pm \\
3.69 \times 10^{5} \mathrm{a}\end{array}$ & $\begin{array}{r}2.38 \times 10^{-7} \pm \\
3.52 \times 10^{-8} \mathrm{c}\end{array}$ & $\begin{array}{c}2.96 \times 10^{6} \pm \\
4.43 \times 10^{5} \mathrm{a}\end{array}$ & $\begin{array}{l}1.29 \times 10^{-7} \pm \\
1.15 \times 10^{-8} \mathrm{~b}\end{array}$ & $\begin{array}{c}5.39 \times 10^{6} \pm \\
0.81 \times 10^{5} \mathrm{a}\end{array}$ & $\begin{array}{l}1.41 \times 10^{-7} \pm \\
2.72 \times 10^{-8} \mathrm{c}\end{array}$ & $\begin{array}{l}5.05 \times 10^{6} \pm \\
10.91 \times 10^{5} \mathrm{a}\end{array}$ & $\begin{array}{l}1.57 \times 10^{-7} \pm \\
1.01 \times 10^{-8} \mathrm{~b}\end{array}$ & $\begin{array}{c}4.42 \times 10^{6} \pm \\
2.92 \times 10^{5} \mathrm{a}\end{array}$ & $\begin{array}{l}1.38 \times 10^{-7} \pm \\
1.01 \times 10^{-8} \mathrm{~b}\end{array}$ & $\begin{array}{c}5.06 \times 10^{6} \pm \\
3.55 \times 10^{5} \mathrm{a}\end{array}$ \\
\hline
\end{tabular}

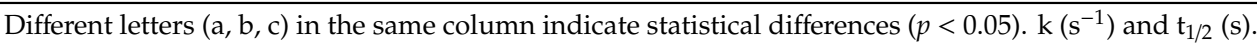

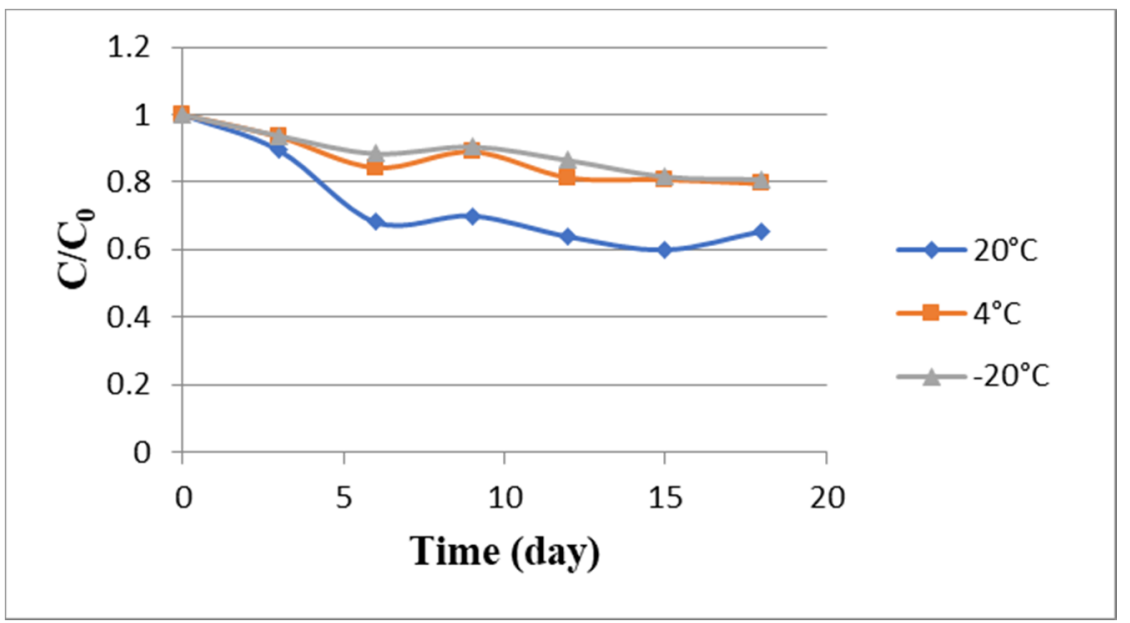

Figure 5. Degradation kinetics of Roselle anthocyanin in $\mathrm{SAFA}_{m}$ during storage at different temperatures. 


\section{Materials and Methods}

\subsection{Plant Material}

Roselle collected from the experimental farms of the University of Agriculture of Kétou, located in Kétou province, Benin Republic. The fresh Roselle calyces were sun-dried for 7 days. The dried calyces were packed into cleaned and sterilized brown bottles and kept at $4{ }^{\circ} \mathrm{C}$ for further use. Prior analysis, the dried calyces were pulverized by a disintegrator (Sinbo, coffee and spice grinder, SCM 2934), sieved, and brown bottle at $4{ }^{\circ} \mathrm{C}$.

\subsection{Chemicals and Reagents}

Distilled water purified by a Millipore-Q system (Millipore Billerica, Massachusetts, USA). Methanol ( $\geq 99,8 \%$ ), 2,2-diphenyl-1-picrylhydrazyl (DPPH), 2,4,6-tris(2-pyridyl)-s-triazine (TPTZ, $\geq 99.0 \%)$, Trolox (97\%), sodium nitrite (99-100.5\%), hydrochloric acid (36.5-38\%), (-)- epicatechin, gallic acid ( $\geq 99.0)$ and sodium carbonate (99.5-100.5\%) were bought from Sigma-Aldrich. Ethanol $(\geq 99.9 \%)$ purchased from Isolab. Folin-Ciocalteu reagent, aluminum chloride, iron (III) chloride, iron sulfate heptahydrate ( $\geq 99.5 \%)$ and formic acid (98-100\%) brought from Merck. Sodium acetate anhydrous $(\geq 99.0 \%)$, glacial acetic acid $(99.5 \%)$, potassium chloride $(\geq 99.0 \%)$, and Sodium hydroxide $(\geq 97.0 \%)$ obtained from Carlo erba.

\subsection{Deep Eutectic Solvent Preparation}

The Deep Eutectic Solvents (DESs) were prepared based on previously reported methodologies with some changes [55,79]. The DESs made in a molar ratio of two different components consisting of hydrogen bond donor (HBD) and hydrogen bond acceptor (HBA), followed by the addition of 20, 40, 60 , and $80 \%$ of distilled water (Table 1). Sodium acetate used as HBA [79] and formic acid as HBD. Another DES prepared in the molarity ratio of sodium acetate and formic acid (1:2). The molarity ratio-based DES formulated due to the fact that the anhydrous mixtures are very viscous, difficult to manipulate [55], and unsuitable for polyphenolics extraction. The molar ratio mixture prepared by mixing the molar mass of components as gram in appropriate ratios. The molarity ratio mixture prepared by mixing ingredients as molarity in the proper ratios. In this work, DES components were placed in reaction flask at $75{ }^{\circ} \mathrm{C}$ with constant stirring for $2 \mathrm{~h} 30 \mathrm{~min}$ to obtain a homogeneous liquid. The DESs prepared in molar and molarity ratios were encoded as $\mathrm{SAFA}_{0}$, and $\mathrm{SAFA}_{\mathrm{m}}$, respectively.

\subsection{Characterization of DESs}

\subsubsection{Rheology}

The viscosity of DESs was measured using a Rheometer (Buchi, CH-9230 Flawil 1, Switzerland) fitted with a parallel geometry with $20 \mathrm{~mm}$ of diameter and gap $1 \mathrm{~mm}$. The measurements carried out as described in [55].

\subsubsection{Fourier Transformed Infrared (FTIR)}

FTIR analysis of DESs and extracts was carried out using a FTIR Spectrometer (Perkin Elmer, Spectrum-Two, USA, PEService 35). Diamond lens attenuated resistance was used. The spectrometer was adjusted in resolution 4 and by selecting the Norton-Beer $(n-\mathrm{B})$ strong apodization function. The range of all spectra was between the wavenumbers of 4000 and $400 \mathrm{~cm}^{-1}$. Prior to every spectrum, a background reference was taken using an empty cell to ensure no interferences. Then, spectrum intensity was transformed into relative transmittance, $\% \mathrm{~T}$.

\subsection{Extraction with DES and Conventional Solvents}

Ultrasound-assisted extractions (UAE) performed in a sonication water bath (WUC-A03H, daihan scientific Co., Ltd. Seoul, Korea). Distilled water, 70\% ethanol, and methanol were used 
as conventional solvents as they have exhibited high extraction performance of anthocyanins from Roselle [6,14,16,17]. $0.5 \mathrm{~g}$ of comminuted Roselle calyces added with $20 \mathrm{~mL}$ of conventional solvents and DESs. The mixture was ultrasonicated in an ultrasonic bath at room temperature $\left(25^{\circ} \mathrm{C}\right)$ for $20 \mathrm{~min}$. The samples were left to cool and then filtered.

\subsection{Optimization Parameters of DES and Extraction with Response Surface Methodology}

The polyphenolic yield is affected by different operational factors such as temperature, time, liquid-solid ratio, the molar ratio of DES, speed of agitator and particle size. Herein, only three of them examined: Liquid-to-solid ratio, molarity ratio, and additional water content. The DES that provides the highest yield of anthocyanin was selected for the optimization process.

The optimization parameters of the DES examined systematically using response surface methodology based on the three-level Box-Behnken design (Design expert software 9.0). The experimental design carried out with three independent variables of $X_{1}$ (molarity ratio), $X_{2}$ (additional water content), and $X_{3}$ (solvent to solid ratio). The actual and coded values of the independent variables presented in Table 7 . The combinations of the molarity ratio of sodium acetate (1) to formic acid (1, 2.5 and 4), additional water $(0 \%, 30 \%$ and $60 \%)$ and solvent to solid ratio $(10: 0.5,25: 0.5$ and $40: 0.5 \mathrm{~mL} / \mathrm{g})$ were independent variables chosen for UAE. These variables regrouped in 17 experimental points, including five replicates at the central point. Total anthocyanin, total phenolic content, FRAP, DPPH radical scavenging activity, and total flavonoid values investigated as the responses $(\mathrm{Y})$ for the design experiment. The experimental points, together with responses, were displayed in Table 3 . The experimental data fitted to the following quadratic polynomial model:

$$
Y=\beta 0+\sum_{i=1}^{3} \beta i X i+\sum_{i=1}^{3} \beta i i X i i+\sum_{i=1}^{2} \sum_{j=i+1}^{3} \beta i j X i X j
$$

Table 7. Actual and coded values of independent variables.

\begin{tabular}{cccc}
\hline \multirow{2}{*}{ Coded Values } & \multicolumn{3}{c}{ Actual Values } \\
\cline { 2 - 4 } & $\mathbf{X}_{\mathbf{1}}$ & $\mathbf{X}_{\mathbf{2}}$ & $\mathbf{X}_{\mathbf{3}}$ \\
\hline-1 & $1: 1$ & 0 & 10 \\
0 & $1: 2.5$ & 30 & 25 \\
+1 & $1: 4$ & 60 & 40 \\
\hline $\mathrm{X}_{1}$ (Molarity ratio); $\mathrm{X}_{2}$ (Additional water, \%) and $\mathrm{X}_{3}$ (Solvent ratio, $\mathrm{mL}$ ).
\end{tabular}

\subsection{Determination of Total Phenolic Content (TPC)}

The TPC of Roselle extracts was determined using the Folin-Ciocalteu method [51,60]. A UV-spectrophotometer (Thermo Spectronic) used to read absorbance at $760 \mathrm{~nm}$, and the TPC in each extract was calculated from a calibration curve $\left(Y=0.0009 x-0.0125 ; R^{2}=0.9977\right)$, using gallic acid as a standard. The results were given as $\mathrm{mg}$ gallic acid equivalent (GAE) $\mathrm{g}^{-1} \mathrm{dw}$.

\subsection{Determination of Total Flavonoid (TFC)}

The total flavonoid was determined using a modified protocol $[51,57,80]$. The absorbance was measured at $510 \mathrm{~nm}$ after $10 \mathrm{~min}$ in the dark at room temperature. The TFC was calculated from a calibration curve using epicatechin as standard $\left(Y=17.062 x+0.0152 ; R^{2}=0.9994\right)$. The results estimated as $\mathrm{mg}$ epicatechin equivalents (ECE) $\mathrm{g}^{-1} \mathrm{dw}$.

\subsection{Determination of Total Anthocyanin (TACN)}

A modified $\mathrm{pH}$ differential method [48] was employed to quantify the total anthocyanin of Roselle calyces. Briefly, $0.05 \mathrm{~mL}$ aliquot of the extract diluted with $1.95 \mathrm{~mL}$ of buffer (consisting of $1.86 \mathrm{~g}$ of 
$\mathrm{KCl}, 980 \mathrm{~mL}$ of distilled water and $6.3 \mathrm{~mL} \mathrm{HCl}), \mathrm{pH} 1.0$ and another $0.05 \mathrm{~mL}$ aliquot of the extract diluted with $1.95 \mathrm{~mL}$ of buffer, (consisting of $54.43 \mathrm{~g}$ of sodium acetate, $960 \mathrm{~mL}$ distilled water and $20 \mathrm{~mL} \mathrm{HCl}$ ) solution $\mathrm{pH}$ 4.5. The buffer solutions completed up to $1 \mathrm{~L}$ with distilled water. Afterward, the absorbance measured at $518 \mathrm{~nm}$, and the total anthocyanin content was calculated in function of mg delphinidin-3-sambubioside equivalent (D3S E) $\mathrm{g}^{-1}$ with the following equation,

$$
\operatorname{TACN}(m g / k g)=\frac{A_{t} \times M_{w} \times D_{f} \times 1000}{\varepsilon \times l}
$$

where $\mathrm{A}=\left(\right.$ Absorbance $_{518 \mathrm{~nm}}-$ Absorbance $\left._{700 \mathrm{~nm}}\right) \mathrm{pH} 1.0-\left(\right.$ Absorbance $_{518 \mathrm{~nm}}-$ Absorbance $\left._{700 \mathrm{~nm}}\right) \mathrm{pH}$ $4.5 ; \mathrm{M}_{\mathrm{W}}$ (molecular weight $)=571 \mathrm{~g} \cdot \mathrm{mol}^{-1}$ for D3S, $\mathrm{DF}=$ dilution factor established in $\mathrm{D}, 1=$ pathlength in $\mathrm{cm}$ and $\varepsilon=26,900$ molar extinction coefficient, in $\mathrm{L} \times \mathrm{mol}^{-1} \times \mathrm{cm}^{-1}$, for delphinidin-3-sambubioside.

\subsection{Determination of Ferric Reducing Antioxidant Power (FRAP)}

FRAP assay performed according to the procedure of $[62,80]$. The FRAP values of the extracts were calculated from the calibration curve $\left(\mathrm{Y}=0.8325-0.0936 ; \mathrm{R}^{2}=0.9966\right)$ using $\mathrm{FeSO}_{4}$ as a standard. The results were given as $\mathrm{mmol} \mathrm{FeSO}_{4}$ equivalents (mmol ISE $\mathrm{g}^{-1} \mathrm{dw}$ ) [81].

\subsection{Determination of the DPPH Radical Scavenging Activity}

DPPH radical scavenging activity determined according to previous studies [51,82,83]. An aliquot of $50 \mu \mathrm{L}$ of the sample added with $1 \mathrm{~mL}$ DPPH solution $(0.06 \mathrm{mM}$ in $80 \%$ methanol). The absorbance at $517 \mathrm{~nm}$ was recorded. The DPPH solution used as control. The reduction ratio of DPPH determined with the following equation,

$$
\text { Reduction }(\%)=\left(\frac{A_{c}-A_{s}}{A_{c}}\right) \times 100
$$

where Ac $=$ Absorbance of control and As $=$ Absorbance of extract. The DPPH radical scavenging activity in each extract was calculated from a calibration curve $\left(Y=149.11 x-0.7773 ; R^{2}=0.9977\right)$ considering the reduction ratio as $\mathrm{Y}$ and using Trolox as a standard. The results were given as mmol Trolox equivalent (TE) $\mathrm{g}^{-1} \mathrm{dw}$ [84].

\subsection{Stability Tests}

\subsubsection{Thermal Stability}

For the thermal stability, $10 \mathrm{~mL}$ of Roselle extracts were put in the brown bottles with screw caps and placed in a preheated water bath at $100,80,60$ and $40{ }^{\circ} \mathrm{C}$. Three bottles of each group were removed from the water bath after 20,40, 60, 80 and $100 \mathrm{~min}$ and cooled to room temperature. To evaluate the kinetic modeling of TPC, TFC, TACN, DPPH radical scavenging and FRAP values of DES extracts of Roselle, the first-order reaction rate constant $(\mathrm{k})$ calculated $[58,85]$,

$$
\ln \left(\frac{C_{t}}{C_{0}}\right)=-\mathrm{kt}
$$

where $\mathrm{k}$ is the constant rate $\left(\mathrm{s}^{-1}\right), \mathrm{C}_{0}$ is the initial concentration and $\mathrm{C}_{\mathrm{t}}$ is the concentration after the heating time $(\mathrm{t})$ at a given temperature.

The kinetics of thermal degradation of anthocyanin of Roselle was evaluated with parameter activation energy (Ea) which was determined as described in [74],

$$
\frac{k}{k_{r e f}}=\exp \left(\frac{-E a}{R}\left(\frac{1}{T}-\frac{1}{T_{r e f}}\right)\right)
$$


where $\mathrm{k}$ is the constant rate $\left(\mathrm{s}^{-1}\right), \mathrm{k}_{\text {ref }}$ is the constant rate $\left(\mathrm{s}^{-1}\right)$ of a reference temperature $\mathrm{T}_{\text {ref }}(\mathrm{K}) \cdot 40^{\circ} \mathrm{C}$ considered as reference temperature in the present study. Ea is the activation energy $\left(\mathrm{J} \mathrm{mol}^{-1}\right)$ and $\mathrm{R}$ is the universal gas constant $\left(8.32 \mathrm{~J} \mathrm{~mol}^{-1} \mathrm{~K}^{-1}\right)$.

\subsubsection{Storage Stability}

The effect of storage time was investigated at $-20^{\circ} \mathrm{C}, 4{ }^{\circ} \mathrm{C}$, and ambient conditions in the dark. $10 \mathrm{~mL}$ of Roselle extracts were put in brown bottles and placed in the dark at $-20^{\circ} \mathrm{C}, 4^{\circ} \mathrm{C}$ and ambient temperature $\left(20^{\circ} \mathrm{C}\right)$. Three bottles of each group were removed and analyzed at days $0,3,7,15$ and 18. The first-order rate constant $(\mathrm{k})$ and half-life time $\left(\mathrm{t}_{1 / 2}\right)$ used to determine the kinetic modeling of anthocyanin degradation during the storage [14,58]:

$$
t_{1 / 2}=\frac{-\ln (0,5)}{k}
$$

\subsection{Data and Statistical Analyses}

All studies were performed in triplicates and the mean values were determined. The software Design Expert 9.0 (Trial version, Stat-Ease Inc., Mineapolis, MN USA) was used to design the experimentation along with data analysis. ANOVA was used to determine the statistical relationship between factors. The adequacy of the models obtained was ascertained by screening the $R^{2}$, adjusted $R^{2}$, coefficient of variation (CV) and the value of Fisher's test (F-value). The significance of the models and regression coefficients were measured at $p<0.05$. The relationship between independent variables and responses was checked by $3 \mathrm{D}$ graphics. The optimum conditions were determined according to the desirability function. One-way statistical analyses were carried out by ANOVA with post-hoc Duncan's test using SPSS (version 21). The significance of the results was assessed at $p \leq 0.05$.

\section{Conclusions}

The analysis of the effect of water addition revealed that the viscosity and DES nanostructure decreased upon water addition. However, the extraction of phytochemical compounds and the antioxidant properties of Roselle increased considerably after the water introduction. SAFA $m$ with 1:2 molarity ratio was revealed to be the most efficient for the extraction of anthocyanins and polyphenol antioxidants from Roselle calyces when compared to $\mathrm{SAFA}_{0}, \mathrm{SAFA}_{20}, \mathrm{SAFA}_{40}, \mathrm{SAFA}_{60}, \mathrm{SAFA}_{80}$ and conventional solvents. Subsequently, this DES was selected for the optimization using a Box-Behnken design paired with response surface methodology to determine the optimum point for the extraction of maximum anthocyanins from Roselle. The optimum point was determined as 1:3.6 molarity ratio, $0 \%$ additional water and $10 \mathrm{~mL}$ solvent ratio. Under these optimum conditions, TPC, TFC, TACN, FRAP and DPPH radical scavenging were found to be $233.26 \mathrm{mg} \mathrm{GAE} / \mathrm{g}, 10.14 \mathrm{mg} \mathrm{ECE} / \mathrm{g}$, $10.62 \mathrm{mg}$ D3S/g, $493.45 \mathrm{mmol}$ ISE/g, and $343.41 \mathrm{mmol} \mathrm{TE} / \mathrm{g}$, respectively. The thermal and storage tests performed on Roselle extracts showed that the phytochemical compounds mainly anthocyanins were more stable in $\mathrm{SAFA}_{\mathrm{m}}$. This novel DES represented a green and sustainable solvent for the extraction of bioactive compounds.

Author Contributions: Conceptualization, methodology, formal analysis, writing original draft, O.Z.; conceptualization, methodology, supervision, writing, visualization, data curation; supervision, visualization, data curation, writing-review and editing, I.K., T.M.S.A. and C.M.G. All authors have read and agreed to the published version of the manuscript.

Funding: This research received no external funding.

Conflicts of Interest: The authors declare that there is no conflict of interest. 


\section{References}

1. Badreldin, H.A.; Naser Al, W.; Gerald, B. Phytochemical, pharmacological and toxicological aspects of Hibiscus sabdariffa L.: A review. Phytother. Res. 2005, 19, 369-375.

2. Maganha, E.G.; da Costa Halmenschlager, R.; Rosa, R.M.; Henriques, J.A.P.; de Paula Ramos, A.L.L.; Saffi, J. Pharmacological evidences for the extracts and secondary metabolites from plants of the genus Hibiscus. Food Chem. 2010, 118, 1-10. [CrossRef]

3. McKay, D.; Blumberg, J. Hibiscus tea (Hibiscus sabdariffa L.) lowers blood pressure in pre-and mildly hypertensive adults. FASEB J. 2007, 21, 1-6.

4. Prenesti, E.; Berto, S.; Daniele, P.G.; Toso, S. Antioxidant power quantification of decoction and cold infusions of Hibiscus sabdariffa flowers. Food Chem. 2007, 100, 433-438. [CrossRef]

5. Amin, A.; Hamza, A.A. Hepatoprotective effects of Hibiscus, Rosmarinus and Salvia on azathioprine-induced toxicity in rats. Life Sci. 2005, 77, 266-278. [CrossRef]

6. Mohd-Esa, N.; Hern, F.S.; Ismail, A.; Yee, C.L. Antioxidant activity in different parts of roselle (Hibiscus sabdariffa L.) extracts and potential exploitation of the seeds. Food Chem. 2010, 122, 1055-1060. [CrossRef]

7. Zannou, O.; Kelebek, H.; Selli, S. Elucidation of key odorants in Beninese Roselle (Hibiscus sabdariffa L.) infusions prepared by hot and cold brewing. Food Res. Int. 2020, 133, 109133. [CrossRef] [PubMed]

8. De Moura, S.C.S.R.; Schettini, G.N.; Garcia, A.O.; Gallina, D.A.; Alvim, I.D.; Hubinger, M.D. Stability of hibiscus extract encapsulated by ionic gelation incorporated in yogurt. Food Bioprocess Technol. 2019, 12, 1500-1515. [CrossRef]

9. Galanakis, C.M. The Food systems in the era of the coronavirus (COVID-19) pandemic crisis. Foods 2020, 9, 523. [CrossRef]

10. Zhen, J.; Villani, T.S.; Guo, Y.; Qi, Y.; Chin, K.; Pan, M.H.; Ho, C.T.; Simon, J.E.; Wu, Q. Phytochemistry, antioxidant capacity, total phenolic content and anti-inflammatory activity of Hibiscus sabdariffa leaves. Food Chem. 2016, 190, 673-680. [CrossRef]

11. Owoade, A.; Adetutu, A.; Olorunnisola, O. Identification of phenolic compounds in Hibiscus sabdariffa polyphenolic rich extract (HPE) by chromatography techniques. Br. J. Pharm. Res. 2016, 12, 1-12. [CrossRef]

12. Segura-Carretero, A.; Puertas-Mejía, M.A.; Cortacero-Ramírez, S.; Beltrán, R.; Alonso-Villaverde, C.; Joven, J.; Dinelli, G.; Fernández-Gutiérrez, A. Selective extraction, separation, and identification of anthocyanins from Hibiscus sabdariffa L. using solid phase extraction-capillary electrophoresis-mass spectrometry (time-of-flight/ion trap). Electrophoresis 2008, 29, 2852-2861. [CrossRef] [PubMed]

13. Grajeda-Iglesias, C.; Figueroa-Espinoza, M.C.; Barouh, N.; Baréa, B.; Fernandes, A.; De Freitas, V.; Salas, E. Isolation and characterization of anthocyanins from Hibiscus sabdariffa flowers. J. Nat. Prod. 2016, 79, 1709-1718. [CrossRef] [PubMed]

14. Sinela, A.; Rawat, N.; Mertz, C.; Achir, N.; Fulcrand, H.; Dornier, M. Anthocyanins degradation during storage of Hibiscus sabdariffa extract and evolution of its degradation products. Food Chem. 2017, 214, 234-241. [CrossRef]

15. Mercado-Mercado, G.; Blancas-Benitez, F.J.; Velderrain-Rodríguez, G.R.; Montalvo-González, E.; González-Aguilar, G.A.; Alvarez-Parrilla, E.; Sáyago-Ayerdi, S.G. Bioaccessibility of polyphenols released and associated to dietary fibre in calyces and decoction residues of Roselle (Hibiscus sabdariffa L.). J. Funct. Foods 2015, 18, 171-181. [CrossRef]

16. Ademiluyi, A.O.; Oboh, G.; Agbebi, O.J.; Akinyemi, A.J. Anthocyanin-rich red dye of Hibiscus sabdariffa calyx modulates cisplatin-induced nephrotoxicity and oxidative stress in rats. Int. J. Biomed. Sci. 2013, 9, 243-248.

17. Ozkol, H.U.; Koyuncu, I.; Tuluce, Y.; Dilsiz, N.; Soral, S.; Ozkol, H. Anthocyanin-rich extract from Hibiscus sabdariffa calyx counteracts UVC-caused impairments in rats. Pharm. Biol. 2015, 53, 1435-1441. [CrossRef]

18. Galanakis, C.M. Recovery of high added-value components from food wastes: Conventional, emerging technologies and commercialized applications. Trends Food Sci. Technol. 2012, 26, 68-87. [CrossRef]

19. Galanakis, C.M. Emerging technologies for the production of nutraceuticals from agricultural by-products: A viewpoint of opportunities and challenges. Food Bioprod. Process. 2013, 91, 575-579. [CrossRef]

20. Galanakis, C.M. Separation of functional macromolecules and micromolecules: From ultrafiltration to the border of nanofiltration. Trends Food Sci. Technol. 2015, 42, 44-63. [CrossRef] 
21. Azmir, J.; Zaidul, I.S.M.; Rahman, M.M.; Sharif, K.M.; Mohamed, A.; Sahena, F.; Jahurul, M.H.A.; Ghafoor, K.; Norulaini, N.A.N.; Omar, A.K.M. Techniques for extraction of bioactive compounds from plant materials: A review. J. Food Eng. 2013, 117, 426-436. [CrossRef]

22. Barba, F.J.; Galanakis, C.M.; Esteve, M.J.; Frigola, A.; Vorobiev, E. Potential use of pulsed electric technologies and ultrasounds to improve the recovery of high-added value compounds from blackberries. J. Food Eng. 2015, 167, 38-44. [CrossRef]

23. Bursać Kovačević, D.; Barba, F.J.; Granato, D.; Galanakis, C.M.; Herceg, Z.; Dragović-Uzelac, V.; Putnik, P. Pressurized hot water extraction (PHWE) for the green recovery of bioactive compounds and steviol glycosides from Stevia rebaudiana Bertoni leaves. Food Chem. 2018, 254, 150-157. [CrossRef] [PubMed]

24. Chemat, F.; Vian, M.A.; Cravotto, G. Green extraction of natural products: Concept and principles. Int. J. Mol. Sci. 2012, 13, 8615-8627. [CrossRef] [PubMed]

25. El Kantar, S.; Rajha, H.N.; Boussetta, N.; Vorobiev, E.; Maroun, R.G.; Louka, N. Green extraction of polyphenols from grapefruit peels using high voltage electrical discharges, deep eutectic solvents and aqueous glycerol. Food Chem. 2019, 295, 165-171. [CrossRef] [PubMed]

26. Nagarajan, J.; Wah Heng, W.; Galanakis, C.M.; Nagasundara Ramanan, R.; Raghunandan, M.E.; Sun, J.; Ismail, A.; Beng-Ti, T.; Prasad, K.N. Extraction of phytochemicals using hydrotropic solvents. Sep. Sci. Technol. 2016, 51, 1151-1165. [CrossRef]

27. Nagarajan, J.; Krishnamurthy, N.P.; Nagasundara Ramanan, R.; Raghunandan, M.E.; Galanakis, C.M.; Ooi, C.W. A facile water-induced complexation of lycopene and pectin from pink guava byproduct: Extraction, characterization and kinetic studies. Food Chem. 2019, 296, 47-55. [CrossRef]

28. López, N.; Delso, I.; Matute, D.; Lafuente, C.; Artal, M. Characterization of xylitol or citric acid:choline chloride:water mixtures: Structure, thermophysical properties, and quercetin solubility. Food Chem. 2020, 306, 125610. [CrossRef]

29. Martins, M.A.R.; Pinho, S.P.; Coutinho, J.A.P. Insights into the nature of eutectic and deep eutectic mixtures. J. Solut. Chem. 2019, 48, 962-982. [CrossRef]

30. Wei, Z.; Qi, X.; Li, T.; Luo, M.; Wang, W.; Zu, Y.; Fu, Y. Application of natural deep eutectic solvents for extraction and determination of phenolics in Cajanus cajan leaves by ultra performance liquid chromatography. Sep. Purif. Technol. 2015, 149, 237-244. [CrossRef]

31. Cunha, S.C.; Fernandes, J.O. Extraction techniques with deep eutectic solvents. TrAC-Trends Anal. Chem. 2018, 105, 225-239. [CrossRef]

32. Kachangoon, R.; Vichapong, J.; Santaladchaiyakit, Y.; Burakham, R.; Srijaranai, S. An eco-friendly hydrophobic deep eutectic solvent-based dispersive liquid-liquid microextraction for the determination of neonicotinoid insecticide residues in water, soil and egg yolk samples. Molecules 2020, 25, 2785. [CrossRef] [PubMed]

33. Chakroun, D.; Grigorakis, S.; Loupassaki, S.; Makris, D.P. Enhanced-performance extraction of olive (Olea europaea) leaf polyphenols using L-lactic acid/ammonium acetate deep eutectic solvent combined with $\beta$-cyclodextrin: Screening, optimisation, temperature effects and stability. Biomass Convers. Biorefin. 2019, 1-12. [CrossRef]

34. Skarpalezos, D.; Detsi, A. Deep eutectic solvents as extraction media for valuable flavonoids from natural sources. Appl. Sci. 2019, 9, 4169. [CrossRef]

35. Saha, S.K.; Dey, S.; Chakraborty, R. Effect of choline chloride-oxalic acid based deep eutectic solvent on the ultrasonic assisted extraction of polyphenols from Aegle marmelos. J. Mol. Liq. 2019, 287, 110956. [CrossRef]

36. Dai, Y.; Witkamp, G.J.; Verpoorte, R.; Choi, Y.H. Tailoring properties of natural deep eutectic solvents with water to facilitate their applications. Food Chem. 2015, 187, 14-19. [CrossRef]

37. Liu, X.; Fu, N.; Zhang, Q.; Cai, S.; Wang, Q.; Han, D.; Tang, B. Green tailoring with water of choline chloride deep eutectic solvents for the extraction of polyphenols from palm samples. J. Chromatogr. Sci. $2019,57,272-278$.

38. Li, T.; Song, Y.; Li, J.; Zhang, M.; Shi, Y.; Fan, J. New low viscous hydrophobic deep eutectic solvents in vortex-assisted liquid-liquid microextraction for the determination of phthalate esters from food-contacted plastics. Food Chem. 2020, 309, 125752. [CrossRef]

39. Vilková, M.; Justyna, P.; Andruch, V. The role of water in deep eutectic solvent-base extraction. J. Mol. Liq. 2019, 291, 111301. [CrossRef] 
40. Gabriele, F.; Chiarini, M.; Germani, R.; Tiecco, M.; Spreti, N. Effect of water addition on choline chloride/glycol deep eutectic solvents: Characterization of their structural and physicochemical properties. J. Mol. Liq. 2019, 291, 111301. [CrossRef]

41. Ozturk, B.; Parkinson, C.; Gonzalez-Miquel, M. Extraction of polyphenolic antioxidants from orange peel waste using deep eutectic solvents. Sep. Purif. Technol. 2018, 206, 1-13. [CrossRef]

42. Barbieri, J.B.; Goltz, C.; Batistão Cavalheiro, F.; Theodoro Toci, A.; Igarashi-Mafra, L.; Mafra, M.R. Deep eutectic solvents applied in the extraction and stabilization of rosemary (Rosmarinus officinalis L.) phenolic compounds. Ind. Crops Prod. 2020, 144, 112049. [CrossRef]

43. Buldo, M.; Cicci, A.; Sed, G.; Sapone, V.; Bravi, M. Detoxification of olive mill wastewaters by liquid-liquid extraction with natural deep eutectic solvents. Chem. Eng. Trans. 2019, 74, 1495-1500.

44. Athanasiadis, V.; Grigorakis, S.; Lalas, S.; Makris, D.P. Highly efficient extraction of antioxidant polyphenols from Olea europaea leaves using an eco-friendly glycerol/glycine deep eutectic solvent. Waste Biomass Valorization 2018, 9, 1985-1992. [CrossRef]

45. Pal, C.B.T.; Jadeja, G.C. Microwave-assisted extraction for recovery of polyphenolic antioxidants from ripe mango (Mangifera indica L.) peel using lactic acid/sodium acetate deep eutectic mixtures. Food Sci. Technol. Int. 2020, 26, 78-92. [CrossRef]

46. Lopez, A.; Iguaz, A.; Esnoz, A.; Virseda, P. Thin-layer drying behaviour of vegetable wastes from wholesale market. Dry. Technol. 2020, 18, 995-1006. [CrossRef]

47. Pinela, J.; Prieto, M.A.; Pereira, E.; Jabeur, I.; Barreiro, M.F.; Barros, L.; Ferreira, I.C.F.R. Optimization of heatand ultrasound-assisted extraction of anthocyanins from Hibiscus sabdariffa calyces for natural food colorants. Food Chem. 2019, 275, 309-321. [CrossRef]

48. Daniel, D.L.; Huerta, B.E.B.; Sosa, I.A.; Mendoza, M.G.V. Effect of fixed bed drying on the retention of phenolic compounds, anthocyanins and antioxidant activity of roselle (Hibiscus sabdariffa L.). Ind. Crops Prod. 2012, 40, 268-276. [CrossRef]

49. Kurtulbaş, E.; Pekel, A.G.; Bilgin, M.; Makris, D.P.; Şahin, S. Citric acid-based deep eutectic solvent for the anthocyanin recovery from Hibiscus sabdariffa through microwave-assisted extraction. Biomass Convers. Biorefin. 2020, 1-10. [CrossRef]

50. Florindo, C.; Oliveira, F.S.; Rebelo, L.P.N.; Fernandes, A.M.; Marrucho, I.M. Insights into the synthesis and properties of deep eutectic solvents based on cholinium chloride and carboxylic acids. ACS Sustain. Chem. Eng. 2014, 2, 2416-2425. [CrossRef]

51. Zannou, O.; Koca, I. Optimization and stabilization of the antioxidant properties from Alkanet (Alkanna tinctoria) with natural deep eutectic solvents. Arab. J. Chem. 2020, 13, 6437-6450. [CrossRef]

52. Hammond, O.S.; Bowron, D.T.; Edler, K.J. The effect of water upon deep eutectic solvent nanostructure: An unusual transition from ionic mixture to aqueous solution. Angew. Chemie Int. Ed. 2017, 56, 9782-9785. [CrossRef] [PubMed]

53. Dai, Y.; van Spronsen, J.; Witkamp, G.J.; Verpoorte, R.; Choi, Y.H. Natural deep eutectic solvents as new potential media for green technology. Anal. Chim. Acta. 2013, 766, 61-68. [CrossRef] [PubMed]

54. Dai, Y.; Rozema, E.; Verpoorte, R.; Choi, Y.H. Application of natural deep eutectic solvents to the extraction of anthocyanins from Catharanthus roseus with high extractability and stability replacing conventional organic solvents. J. Chromatogr. A. 2016, 1434, 50-56. [CrossRef] [PubMed]

55. Aroso, I.M.; Paiva, A.; Reis, R.L.; Duarte, A.R.C. Natural deep eutectic solvents from choline chloride and betainePhysicochemical properties. J. Mol. Liq. 2017, 241, 654-661. [CrossRef]

56. Cvjetko Bubalo, M.; Ćurko, N.; Tomašević, M.; Kovačević Ganić, K.; Radojcic Redovnikovic, I. Green extraction of grape skin phenolics by using deep eutectic solvents. Food Chem. 2016, 200, 159-166. [CrossRef] [PubMed]

57. Lakka, A.; Grigorakis, S.; Karageorgou, I.; Batra, G.; Kaltsa, O.; Bozinou, E.; Lalas, S.; Makris, D.P. Saffron processing wastes as a bioresource of high-value added compounds: Development of a green extraction process for polyphenol recovery using a natural deep eutectic solvent. Antioxidants 2019, 8, 586. [CrossRef]

58. Dai, Y.; Verpoorte, R.; Choi, Y.H. Natural deep eutectic solvents providing enhanced stability of natural colorants from safflower (Carthamus tinctorius). Food Chem. 2014, 159, 116-121. [CrossRef]

59. Liu, Y.; Li, J.; Fu, R.; Zhang, L.; Wang, D.; Wang, S. Enhanced extraction of natural pigments from Curcuma longa L. using natural deep eutectic solvents. Ind. Crops Prod. 2014, 140, 111620. [CrossRef] 
60. Wan Mahmood, W.M.A.; Lorwirachsutee, A.; Theodoropoulos, C.; Gonzalez-Miquel, M. Polyol-Based deep eutectic solvents for extraction of natural polyphenolic antioxidants from Chlorella vulgaris. ACS Sustain. Chem. Eng. 2019, 7, 5018-5026. [CrossRef]

61. Zhou, P.; Wang, X.; Liu, P.; Huang, J.; Wang, C.; Pan, M.; Kuang, Z. Enhanced phenolic compounds extraction from Morus alba L. leaves by deep eutectic solvents combined with ultrasonic-assisted extraction. Ind. Crops Prod. 2018, 120, 147-154. [CrossRef]

62. Shang, X.; Dou, Y.; Zhang, Y.; Tan, J.N.; Liu, X.; Zhang, Z. Tailor-made natural deep eutectic solvents for green extraction of isoflavones from chickpea (Cicer arietinum L.) sprouts. Ind. Crops Prod. 2019, 140, 111724. [CrossRef]

63. Odabaş, H.I.; Koca, I. Application of response surface methodology for optimizing the recovery of phenolic compounds from hazelnut skin using different extraction methods. Ind. Crops Prod. 2016, 91, 114-124. [CrossRef]

64. Vieira, V.; Prieto, M.A.; Barros, L.; Coutinho, J.A.P.; Ferreira, I.C.F.R.; Ferreira, O. Enhanced extraction of phenolic compounds using choline chloride based deep eutectic solvents from Juglans regia L. Ind. Crops Prod. 2018, 115, 261-271. [CrossRef]

65. Obluchinskaya, E.D.; Daurtseva, A.V.; Pozharitskaya, O.N.; Flisyuk, E.V.; Shikov, A.N. Natural deep eutectic solvents as alternatives for extracting phlorotannins from brown algae. Pharm. Chem. J. 2019, 53, $243-247$. [CrossRef]

66. Balaraman, H.B.; Sivasubramaniyam, A.; Rathnasamy, S.K. High selective purification of Quercetin from Peanut hull using protic deep eutectic mixture based liquid-liquid microextraction. Microchem. J. 2020, 152, 104444. [CrossRef]

67. Ji, Y.; Meng, Z.; Zhao, J.; Zhao, H.; Zhao, L. Eco-friendly ultrasonic assisted liquid-liquid microextraction method based on hydrophobic deep eutectic solvent for the determination of sulfonamides in fruit juices. J. Chromatogr. A 2020, 1609, 460520. [CrossRef]

68. Heidari, H.; Ghanbari-rad, S.; Habibi, E. Optimization deep eutectic solvent-based ultrasound-assisted liquid-liquid microextraction by using the desirability function approach for extraction and preconcentration of organophosphorus pesticides from fruit. J. Food Compos. Anal. 2020, 87, 103389.

69. Zhao, J.; Meng, Z.; Zhao, Z.; Zhao, L. Ultrasound-assisted deep eutectic solvent as green and e fficient media combined with functionalized magnetic multi-walled carbon nanotubes as solid-phase extraction to determine pesticide residues in food products. Food Chem. 2020, 310, 125863. [CrossRef]

70. Galanakis, C.M. Phenols recovered from olive mill wastewater as additives in meat products. Trends Food Sci. Technol. 2018, 79, 98-105. [CrossRef]

71. Galanakis, C.M.; Tsatalas, P.; Galanakis, I.M. Implementation of phenols recovered from olive mill wastewater as UV booster in cosmetics. Ind. Crops Prod. 2018, 111, 30-37. [CrossRef]

72. Oancea, A.; Onofrei, C.; Turturica, M.; Bahrim, G.; Ra, G. The kinetics of thermal degradation of polyphenolic compounds from elderberry (Sambucus nigra L.) extract. Food Sci. Technol. Int. 2014, 24, 361-369. [CrossRef] [PubMed]

73. Radu (Lupoae), D.; Râpeanu, G.; Bahrim, G.E.; Stănciuc, N. Investigations on thermal degradation of phytochemicals from lavender extract. Fascicle VI-Food Technol. 2019, 43, 33-47. [CrossRef]

74. Olivares-tenorio, M.; Verkerk, R.; Van Boekel, M.A.J.S.; Dekker, M. Thermal stability of phytochemicals, HMF and antioxidant activity in cape gooseberry (Physalis peruviana L.). J. Funct. Foods. 2017, 32, 46-57. [CrossRef]

75. Cissé, M.; Bohuon, P.; Sambe, F.; Kane, C.; Sakho, M.; Dornier, M. Aqueous extraction of anthocyanins from Hibiscus sabdariffa: Experimental kinetics and modeling. J. Food Eng. 2012, 109, 16-21. [CrossRef]

76. Cissé, M.; Vaillant, F.; Acosta, O.; Dhuique-Mayer, C. Thermal degradation kinetics of anthocyanins from blood orange, blackberry, and roselle using the arrhenius, eyring, and ball models. J. Agric. Food Chem. 2009, 57, 6285-6291. [CrossRef]

77. Ahmed, J.; Shivhare, U.S.; Raghavan, G.S.V. Thermal degradation kinetics of anthocyanin and visual colour of plum puree. Eur. Food Res. Technol. 2004, 218, 525-528. [CrossRef]

78. Harbourne, N.; Jacquier, J.C.; Morgan, D.J.; Lyng, J.G. Determination of the degradation kinetics of anthocyanins in a model juice system using isothermal and non-isothermal methods. Food Chem. 2008, 111, 204-208. [CrossRef]

79. Pal, C.B.T.; Jadeja, G.C. Deep eutectic solvent-based extraction of polyphenolic antioxidants from onion (Allium cepa L.) peel. J. Sci. Food Agric. 2019, 99, 1969-1979. [CrossRef] 
80. Fawole, O.A.; Opara, U.L.; Theron, K.I. Chemical and phytochemical properties and antioxidant activities of three pomegranate cultivars grown in South Africa. Food Bioprocess Technol. 2011, 5, 2934-2940. [CrossRef]

81. Koca, I.; Karadeniz, B. Antioxidant properties of blackberry and blueberry fruits grown in the Black Sea Region of Turkey. Sci Hortic. 2009, 121, 447-450. [CrossRef]

82. Wang, T.; Guo, N.; Wang, S.X.; Kou, P.; Zhao, C.J.; Fu, Y.J. Ultrasound-negative pressure cavitation extraction of phenolic compounds from blueberry leaves and evaluation of its DPPH radical scavenging activity. Food Bioprod. Process. 2018, 108, 69-80. [CrossRef]

83. Tural, S.; Koca, I. Physico-chemical and antioxidant properties of cornelian cherry fruits (Cornus mas L.) grown in Turkey. Sci. Hortic. 2008, 116, 362-366. [CrossRef]

84. Sathishkumar, R.S.; Sundaramanickam, A.; Srinath, R.; Ramesh, T.; Saranya, K.; Meena, M.; Surya, P. Green synthesis of silver nanoparticles by bloom forming marine microalgae Trichodesmium erythraeum and its applications in antioxidant, drug-resistant bacteria, and cytotoxicity activity. J. Saudi Chem. Soc. 2019, 23, 1180-1191. [CrossRef]

85. Anna, V.S.; Damasceno, L.; Marczak, F.; Tessaro, I.C. Kinetic modeling of anthocyanin extraction from grape Marc. Food Bioprocess Technol. 2013, 6, 3473-3480.

Sample Availability: Samples of the compounds are available from the authors.

(C) 2020 by the authors. Licensee MDPI, Basel, Switzerland. This article is an open access article distributed under the terms and conditions of the Creative Commons Attribution (CC BY) license (http://creativecommons.org/licenses/by/4.0/). 